\title{
Molecular Characterization of the NADPH Oxidase Complex in the Ergot Fungus Claviceps purpurea: CpNox2 and CpPIs1 Are Important for a Balanced Host-Pathogen Interaction
}

\author{
Janine Schürmann, Dagmar Buttermann, Andrea Herrmann, Sabine Giesbert, and Paul Tudzynski \\ Institut für Biologie und Biotechnologie der Pflanzen, Westf. Wilhelms-Universität, Schlossplatz 8, D-48143 Münster, \\ Germany
}

Submitted 7 March 2013. Accepted 10 June 2013.

\begin{abstract}
Reactive oxygen species producing NADPH oxidase (Nox) complexes are involved in defense reactions in animals and plants while they trigger infection-related processes in pathogenic fungi. Knowledge about the composition and localization of these complexes in fungi is limited; potential components identified thus far include two to three catalytical subunits, a regulatory subunit (NoxR), the GTPase Rac, the scaffold protein Bem1, and a tetraspanin-like membrane protein (PIs1). We showed that, in the biotrophic grass-pathogen Claviceps purpurea, the catalytical subunit CpNox1 is important for infection. Here, we present identification of major Nox complex partners and a functional analysis of CpNox2 and the tetraspanin CpPls1. We show that, as in other fungi, Nox complexes are important for formation of sclerotia; CpRac is, indeed, a complex partner because it interacts with $\mathrm{CpNoxR}$, and CpNox1/2 and CpPls1 are associated with the endoplasmatic reticulum. However, unlike in all other fungi, $\Delta$ cppls1 is more similar to $\Delta$ cpnox1 than to $\Delta$ cpnox 2 , and CpNox 2 is not essential for infection. In contrast, $\Delta$ cpnox 2 shows even more pronounced disease symptoms, indicating that Cpnox 2 controls the infection process and moderates damage to the host. These data confirm that fungal Nox complexes have acquired specific functions dependent of the lifestyle of the pathogen.
\end{abstract}

The Ergot fungus, Claviceps purpurea (Fr.) Tul., is a biotrophic pathogen that infects more than 400 plants, including economically important species such as wheat, barley, and rye (Bové 1970; Taber 1985). It has a surprisingly high host range for a biotroph while it is organ specific and only infects the ovaries of flowering grasses in a highly conserved pattern. After germination and penetration of the stigmatic hairs of ovaries, C. purpurea grows completely unbranched within the transmitting tissue, forming bundles of hyphae that are oriented toward the rachilla. As soon as it reaches the base of the ovary, it taps into the vascular tissue and then the fungus undergoes a

J. Schürmann and D. Butterman are co-first authors.

Corresponding author: P. Tudzynski; E-mail: tudzyns@uni-muenster.de

* The $\boldsymbol{e}$-Xtra logo stands for "electronic extra" and indicates that nine supplementary figures and three supplementary tables are published online.

(C) 2013 The American Phytopathological Society marked morphological change to produce frequently branched hyphae, leading to the formation of a mycelial stroma (sphacelium). Interestingly, no further spread of the fungus beyond the rachilla can be observed and a persistent host-pathogen interface is established at this point. At approximately 7 days postinfection (dpi), the plant phloem is enriched with sphaceliumderived conidiospores and these propagules are subsequently secreted along the spikelets. This so-called "honeydew" is the first macroscopic symptom of an infection and leads to further spreading of the disease within a field. Finally, a second morphological switch occurs, as the sphacelium differentiates into sclerotial tissue consisting of storage cells with high lipid content. These cells finally differentiate a hard, purple pigmented sclerotium for overwintering (Kirchhoff 1929; Schürmann and Tudzynski in press; Shaw and Mantle 1980).

We recently demonstrated that CpNox1, a member of the fungal NADPH oxidase (Nox) clade, is essential for this pathogenic development of $C$. purpurea (Giesbert et al. 2008). Deletion mutants of cpnoxl are able to penetrate the host epidermis but are impaired in their ability to colonize the ovary; sclerotia are formed only in rare cases and they do not fully ripen.

Fungal NADPH oxidases are homologues of the intensively studied gp91 ${ }^{\text {phox }}$ protein from animal phagocytic cells (Takemoto et al. 2007). It is the membrane-spanning catalytical subunit of a multi-enzyme complex that produces reactive oxygen species (ROS) during microbial attack and inflammatory reactions. In phagocytes, the Nox complex consists, along with gp91 ${ }^{\text {phox }}$, of the membrane-associated protein $\mathrm{p} 22^{\text {phox }}$ and three cytosolic subunits ( $\mathrm{p} 40^{\text {phox }}, \mathrm{p} 47^{\text {phox }}$, and $\mathrm{p} 67^{\text {phox }}$ ) as well as of the small GTPase Rac. Upon cell activation, the cytosolic components and GTP-bound Rac translocate to the membrane where the active complex is formed and catalyzes the transfer of electrons from NADPH to molecular oxygen, generating superoxide that is converted into different ROS (Lambeth 2004).

In fungi, three different subtypes of Nox enzymes have been identified, of which NoxA (Nox1) and NoxB (Nox2) are homologues of phagocytic gp91 $91^{\text {phox }}$, whereas NoxC is a fungal-specific subtype similar to the plant respiratory burst oxidases (Rboh) (Heller and Tudzynski 2011). Analyses have demonstrated that fungal Nox enzymes are involved in sexual differentiation in the filamentous fungi Aspergillus nidulans (LaraOrtiz et al. 2003), Podospora anserina (Malagnac et al. 2004), and Neurospora crassa (Cano-Dominguez et al. 2008). These results confirm earlier research by Aguirre and collaborators that ROS are required for differentiation in fungi (Hansberg and Aguirre 1990). This knowledge has recently been extended 
to developmental processes in phytopathogens: in the hemibiotroph Magnaporthe oryzae, the Nox complexes are required for development of functional appressoria (Egan et al. 2007; Ryder et al. 2013); in the necrotrophs Botrytis cinerea and Sclerotinia sclerotiorum, they are essential for formation of sclerotia and virulence (Kim et al. 2011; Segmüller et al. 2008; Siegmund et al. 2013). Furthermore, Tanaka and associates (2006) showed that, in the endophyte Epichloe festucae, which is closely related to $C$. purpurea, a Nox enzyme is required to maintain a stable symbiosis with the host.

In principle, the Nox complex composition in fungi seems to be very similar to the mammalian system. Homologues of the regulatory subunit $\mathrm{p} 67^{\text {phox }}$ (NoxR) and the small GTPase Rac have been identified in several fungi (Tudzynski et al. 2012). In $C$. purpurea, the deletion of cprac leads to complete loss of polarity, sporulation, and the ability to penetrate the plant (Rolke and Tudzynski 2008). Fungal Nox regulators (NoxR) contain domains for Rac and Nox binding, as well as a Phox and Bem1 (PB1) domain which, however, differs from the PB1 domain of p6 $7^{\text {phox }}$. Furthermore, it completely lacks the C-terminal Scr homology 3 (SH3) domain necessary for interactions with the other cytosolic subunits (Takemoto et al. 2006). Fungi do not contain homologues of $\mathrm{p} 47^{\text {phox }}, \mathrm{p} 40^{\text {phox }}$, or $\mathrm{p} 22^{\text {phox }}$, leading to the suggestion that functional analogues must be present in fungi. Candidates are the tetraspanin Pls1 as well as the scaffold protein Bem1, which resembles the domain structure of $\mathrm{p} 40^{\text {phox }}$ and $\mathrm{p} 47^{\text {phox }}$. Bem1 is essential for the polarity establishment in yeast (Chenevert et al. 1992) and has recently been shown to be important in the directed cell growth during conidial anastomosis tube formation of $N$. crassa (Schürg et al. 2012). In $E$. festucae, Bem 1 is part of the Nox complex where it directly interacts with NoxR at the hyphal tip (Takemoto et al. 2011). Tetraspanins such as Pls1 are small membrane proteins that were originally identified in mammals, where they are involved in the regulation of differentiation, cell adhesion, and motility. Due to their secondary structure, they act as molecular adaptors in membrane complexes (Hemler 2005). In fungi, they have been associated with Nox 2 because of the co-occurrence of these two genes in fungal genomes (Lambou et al. 2008). Available data thus far confirm this hypothesis because Pls1 and Nox 2 are involved in the same processes in several fungi. In $M$. oryzae, B. cinerea, and Colletotrichum lindemuthianum, Nox2/B as well as Pls1 are required for formation of functional appressoria for the penetration of their host plants, whereas they are essential for ascospore germination in $P$. anserina, a non-appressoria-forming saprophytic fungus (Clergeot et al. 2001; Egan et al. 2007; Gourgues et al. 2004; Lambou et al. 2008; Siegmund et al. 2013; Veneault-Fourrey et al. 2005).

Here, we show that, in Claviceps purpurea, the second catalytical Nox subunit, CpNox2, is important for a balanced (biotrophic) infection of the host. It restricts the severity of disease symptoms because it is responsible for the induction of the second morphological switch in planta, which terminates honeydew production and leads to formation of sclerotia. Furthermore, we present data on the Nox complex composition and demonstrate that, unexpectedly, CpPls1 shares overlapping functions with CpNox1 rather than with CpNox2 during the early stages of an infection, while all three proteins are indispensable for normal sclerotia development in the later infection stages.

\section{RESULTS}

Identification of Nox complex components in $C$. purpurea.

During the lambda library screening approach leading to the identification of CpNox1, a second putative Nox gene was identified (Giesbert et al. 2008). This gene (CPUR_03617.1) has an open reading frame of $1,887 \mathrm{bp}$ (interrupted by one intron of $162 \mathrm{bp}$ ) coding for a polypeptide of 574 amino acids (aa). It showed significant sequence homology to members of the NoxB clade of fungal homologues of gp91 ${ }^{\text {phox }}$ from phagocytes (Aguirre et al. 2005). The gene was named cpnox2 (Supplementary Fig. S1) because it contains characteristic features of this group (Tanaka et al. 2006): six (predicted) transmembrane domains, motifs involved in heme, FAD and NADPH binding, and an N-terminal extension (data not shown).

To identify further components of the Nox complexes in $C$. purpurea, the recently available genomic sequence of $C$. purpurea 20.1 (Schardl et al. 2013) was screened for homologues of other known components. The co-occurrence of Nox 2 and Pls1 genes (Lambou et al. 2008) could also be verified for $C$. purpurea: a gene (CPUR_00527.1; 1,060 bp; 228 aa) related to other Pls1 proteins (Supplementary Fig. S2) was detected encoding a protein with four transmembrane domains (TM) comprising the typical loop organization of Pls1 proteins: a small extracellular loop (ECL1) and a small intracellular loop followed by a large ECL (ECL2). In addition, the conserved cysteine-pattern of ECL2 (CCGY-x(13)-C-x(11)-C-x(14)TM4) as well as the charged or polar amino acids within the TMs of Pls1 proteins could be confirmed (data not shown); hence, the gene was termed cppls1. Furthermore, the screening led to the identification of CpNoxR (CPUR_08910), a putative homologue of the regulatory subunit $\mathrm{p} 67^{\text {phox }}$ containing a PB1 type I/II domain and a TPR interaction motif (data not shown). In addition, cpbeml, a gene with high sequence homology to the scaffold protein Bem1 encoding gene of $S$. cerevisiae (Chenevert et al. 1992), was detected. The predicted protein (CPUR_05119.1) contained two SH3s, a phox homology (PX), and a PB1 type II domain (data not shown) which are characteristic of Bem1 proteins.

\section{Generation of deletion mutants.}

To study the function of these putative components of the $C$. purpurea Nox complex in virulence and development of the Ergot fungus, we generated deletion mutants of cpnox 2 and cppls1 by gene replacement. Polymerase chain reaction (PCR) probes of $5^{\prime}$ - and $3^{\prime}$-flanking regions of the respective genes were joined with phleomycin- or hygromycin-resistance cassettes (Supplementary Figs. S3 and S4; details below). Linear replacement constructs were transformed into protoplasts of wild-type strain Cp20.1. Primary putative deletion transformants for cpnox2 (Supplementary Fig. S5) and cppls1 (Supplementary Fig. S6) were checked by diagnostic PCR analysis for the presence of correctly integrated replacement constructs. From 61 primary transformants obtained for cpnox 2, 1 showed diagnostic PCR fragments; and, from approximately 500 primary transformants obtained for cppls 1,1 deletion mutant could be detected. Single-spore isolations were performed and, finally, for both genes, homokaryotic deletion mutants were isolated. Southern analysis confirmed the lack of the wild-type gene copy and a single integration event in the deletion strains $\Delta$ cpnox2 (Supplementary Fig. S7) and $\Delta$ cppls1 (Supplementary Fig. S8). The homokaryotic deletion mutants of cpnox2 and cppls 1 were used as recipients for complementation constructs containing the whole coding sequences of the respective genes (discussed below). Reintroduction of the full-length gene copies was controlled by PCR (data not shown) and the complemented strains were used as controls during characterization of the knock-out mutants.

\section{CpNox2 has impact on conidial formation but not on germination.}

For induction of conidiation, the deletion strains of cpnox 2 and cppls 1 as well as the wild-type $\mathrm{Cp} 20.1$ were cultivated on 
Mantle agar. Although the strains $\mathrm{Cp} 20.1$ and $\Delta$ cppls1 showed normal sporulation, the deletion mutant $\Delta$ cpnox 2 was slightly reduced in formation of conidia (to approximately 80\%) compared with the other strains. Titers of conidia were adjusted and equal numbers of spores of the strains Cp20.1, $\Delta$ cppls1, and $\Delta$ cpnox 2 were plated out for germination. After an incubation of 4 days, all strains showed a germination rate of approximately $25 \%$ (data not shown).

\section{CpNox2 and CpPls1 are necessary for oxidative stress tolerance.}

To test tolerance toward oxidative stress, the deletion mutants $\Delta$ cpnox1, $\Delta$ cpnox2, and $\Delta$ cppls1 as well as wild-type $\mathrm{Cp} 20.1$ were grown on Mantle agar plates supplemented with menadione (concentrations of 0.05 to $0.45 \mathrm{mM}$ ) (Fig. 1). All tested deletion mutants already showed enhanced sensitivity to oxidative stress at low menadione concentrations $(0.05 \mathrm{mM})$. At menadione concentrations of $0.15 \mathrm{mM}$ and more, a significant reduction $(P<0.001)$ of growth of all three mutants (compared with the wild type) was observed. The deletion mutants of the catalytical subunits cpnoxl and cpnox 2 were completely inhibited at levels of $0.35 \mathrm{mM}$ and above, whereas the $\Delta$ cppls $1 \mathrm{mu}-$ tant was able to grow on all menadione concentrations tested, though significantly reduced compared with the wild type.

\section{CpNox2 and CpPls1 are important for normal pathogenic development.}

For cpnox1, a role in virulence has already been demonstrated (Giesbert et al. 2008). In infection assays in planta, $\Delta$ cpnox1 mutants can penetrate the host plant but are unable to fully colonize the ovarian tissue and, therefore, no normal macroscopic symptoms of successful infection can be observed. Only rarely does infection proceed; then, however, production of honeydew is very restricted and mature sclerotia have never been observed (Giesbert et al. 2008).

To test the impact of the deletion of the other Nox complex genes cpnox 2 and cppls 1 on pathogenic development, pathogenicity assays with both knock-out strains were performed on intact rye plants. The $\Delta$ cpnox 2 mutant strain revealed a remarkable phenotype, with prolonged and therefore massively enhanced production of honeydew and conidiospores (Fig. 2). Exudation began as in the wild-type strain at approximately 7 dpi but failed to stop at approximately $14 \mathrm{dpi}$, in marked contrast to the wild-type strain (Supplementary Table S1) that stopped honeydew secretion and had initiated formation of a sclerotium by this time. In the cpnox 2 deletion mutant, however, this normal sclerotial development failed because the mutant finally produced only small, immature pseudosclerotia. These were smaller than wild-type sclerotia and appeared to have a white or brownish color, rather than the typical purple or black pigmentation (Fig. 3A), a phenotype already reported for strain $\Delta$ cpnox 1 (Giesbert et al. 2008).

To quantify production of honeydew, florets inoculated with spores of $\Delta$ cpnox 2 and wild-type Cp20.1 were encased with plastic collars to collect honeydew dripping off infected florets. After 15 days, up to $1.6 \mathrm{~g}$ of honeydew was harvested from each floret infected with strain $\Delta$ cpnox2, by which time no honeydew had dropped from florets inoculated with the wild type (Fig. 2).

In planta infection of Secale cereale with the $\Delta$ cppls $1 \mathrm{mu}-$ tants resulted in reduced infection rates, because fewer ovaries could be colonized successfully (Fig. 2). In those ovaries where infections were successful, wild-type levels of honeydew formation occurred but only nonripened sclerotia were formed, and these strongly resembled the pseudosclerotia produced by $\Delta$ cpnox 2 (Fig. $3 \mathrm{~A}$ ). In total, honeydew production is reduced due to lower infection rates.
For further analysis, sclerotia of the wild-type $\mathrm{Cp} 20.1$ and pseudosclerotia produced by $\Delta$ cpnox 2 and $\Delta$ cppls 1 were collected and tested for their starch content by iodine-potassium staining, because they showed similarities to the color and shape of uninfected seed from their external appearance as well as in cross sections, where a white biomass was visible (Fig. 3D). However, no starch was detected in the pseudosclerotia, suggesting that the white biomass was fungal, though lacking the typical dark pigmentation (discussed below).

Stem sections from florets infected with $\Delta$ cpnox 2 and wildtype 20.1 were then placed on agar plates to test whether the increased production of honeydew in the deletion mutant $\Delta$ cpnox 2 was induced by enhanced colonization of the host tissue associated with hyphal growth beyond the rachilla, a development that never happens in wild-type in planta infections. No outgrowth could be detected in host stems for the tested

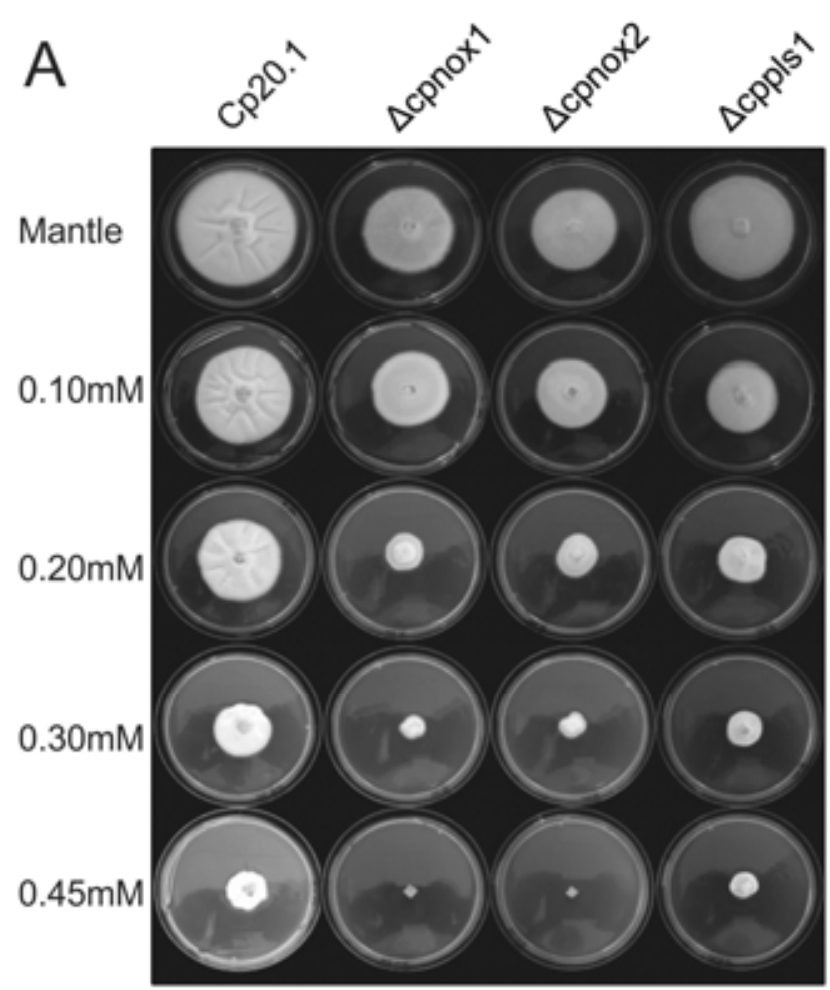

B

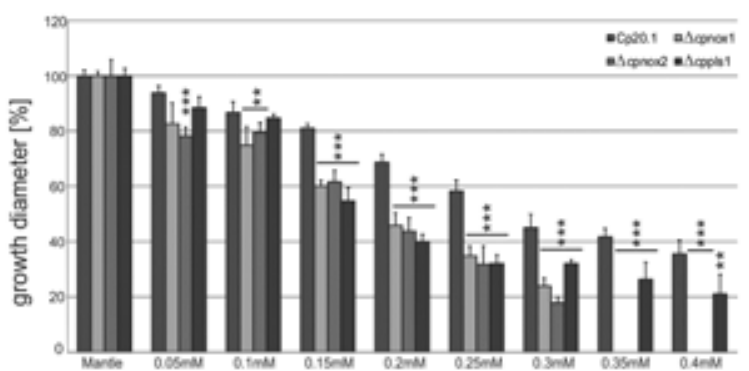

Fig. 1. Oxidative stress sensitivity of $\Delta$ cpnox $1, \Delta$ cpnox $2, \Delta$ cppls 1 , and wild-type Cp20.1. Mycelial plugs of the Nox complex mutants and wildtype Cp20.1 were grown on Mantle agar plates supplemented with menadione in concentrations of 0.05 to $0.45 \mathrm{mM}$. Nonsupplemented Mantle media were inoculated as controls. A, Plate assay. Pictures were taken after 15 days. B, Statistical evaluation of colony growth. Relative colony diameters (compared with growth on nonsupplemented Mantle medium) of the Nox complex mutants and wild-type Cp20.1 on media containing menadione. Indicated values are means of six different measurements after 15 days; standard deviations are indicated by bars; concentrations of menadione are indicated at the bottom. Asterisks above the bars denote significant differences in the measurements of the indicated strains to the wild type; $* *$ and $* * *=P<0.01$ and 0.001 , respectively 
strains (Supplementary Fig. S9). Additionally, aniline-bluestained cross sections of whole florets infected with $\Delta$ cpnox2 and wild-type $\mathrm{Cp} 20.1$ strains were analyzed microscopically. No colonization of the rachilla could be detected, indicating that the mutant stops infection at the flower base like the wild type (Fig. 3C). This experiment also confirmed the starch assay result, because aniline-blue-stained cross sections clearly indicated that the immature pseudosclerotia from $\Delta$ cpnox 2 consisted of fungal biomass (Fig. 3B).

To analyze the defects in pathogenic development during early steps of infection in more detail, isolated rye ovaries were inoculated in vitro (Scheffer and Tudzynski 2006) with conidia of both mutants and the wild type. After 6 days, development of infection was monitored by aniline-blue staining of the ovaries after transverse sectioning (Fig. 4). Although the deletion mutant $\Delta$ cpnox 2 showed an infection pattern like the wild-type Cp20.1 that starts with penetration of the stigmatic hairs and growth down the style and around the ovule, the deletion mutant $\Delta$ cppls1 was less successful in colonization of the host tissue, and it could not be detected in all inoculated ovaries. Ovaries that were visually colonized by the $\Delta$ cppls1 mutant showed different stages of fungal infection. In some ovaries, the fungus was detected only within the stigmatic hairs whereas, in other ovaries, infection had proceeded to the transmitting tissue. However, some ovaries infected with the $\Delta$ cppls1 strain were indistinguishable from ovaries infected with $\Delta$ cpnox 2 or the wild-type Cp20.1 (Fig. 4).

\section{Expression studies.}

Because the pathogenicity assays showed an involvement of both CpNox2 and CpPls1 during colonization of host tissue and differentiation of sclerotia, we studied the expression of the corresponding genes in planta. Because of the difficulty of obtaining larger amounts of fungal RNA from the tiny infected ovaries, we used quantitative reverse-transcription (qRT)-PCR to quantify the mRNA levels. We chose three fungal housekeeping genes with different expression levels as references: $\beta$-tubulin (CCE34429.1), $\gamma$-actin (AEI72275.1), and glyceraldehyde-3phosphate dehydrogenase ( $g p d$ ) (X73282.1) (discussed below). As a negative control, cDNA from noninfected rye florets was used. No fragments were amplified when using cDNA from noninfected plant material as a template and primers specific for C. purpurea. Cpnox2 expression shows a strong increase toward late stages of infection (Fig. 5A). This tendency was confirmed in three biological replicates whereas, on the other hand, cppls 1 expression was more or less constitutive throughout the whole infection process in the wild type on rye, although the expression level varied between biological repeats (data not shown).
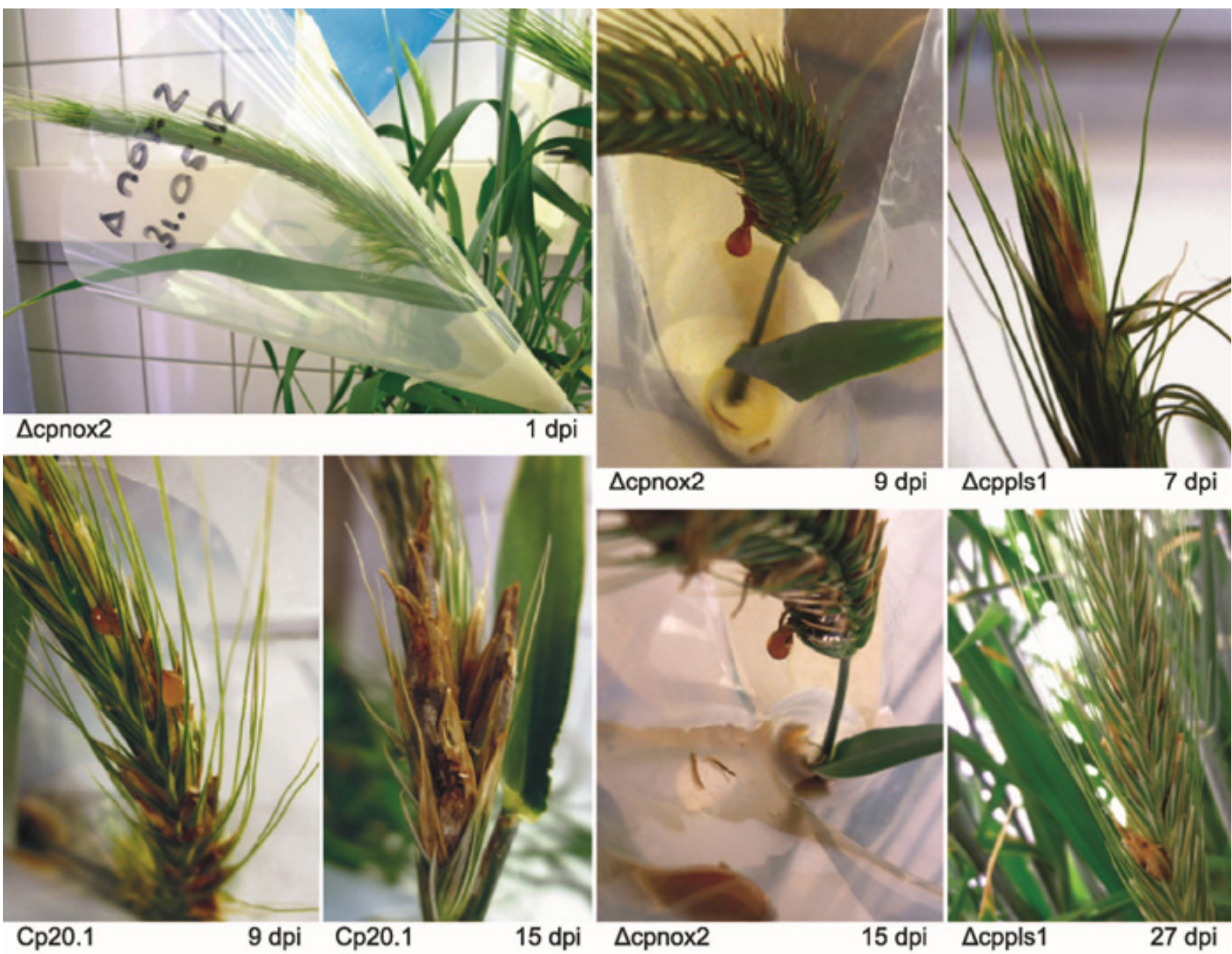

\section{Cp20.1}

$9 \mathrm{dpi}$

$15 \mathrm{dpi}$
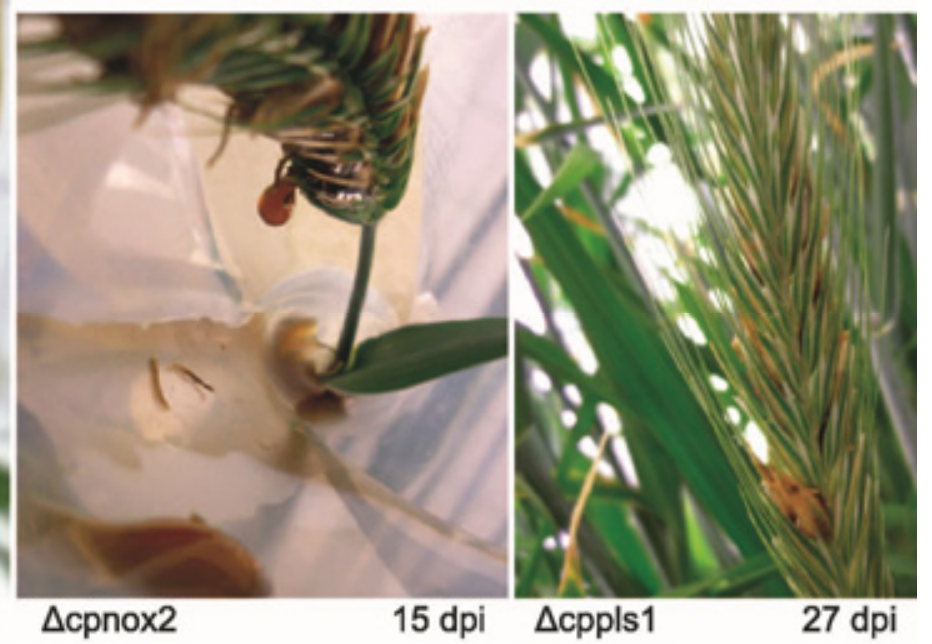

Fig. 2. In planta pathogenicity assays of Claviceps purpurea $\Delta$ cpnox $2, \Delta$ cppls 1 , and wild-type Cp20.1 on intact rye plants. Rye ears were infected with conidiospore suspensions of $C$. purpurea wild-type strain Cp20.1 and mutant strains $\Delta$ cpnox 2 and $\Delta$ cppls1. Honeydew formation and sclerotial development were followed for 3 weeks. Inoculated ears were separated from one another to avoid cross contaminations after onset of symptoms of infection, and plastic collars were used for collection of honeydew produced by $\Delta$ cpnox 2 ; dpi $=$ days postinoculation. 
To further characterize the loss of coloration in sclerotia of the deletion mutants, another qRT-PCR approach was performed. Bioinformatical analyses had revealed a secondary metabolite gene cluster which is putatively involved in biosynthesis of the purple pigment characteristic for sclerotial tissue in C. purpurea (B. Oeser and P. Tudzynski, unpublished data); therefore, the expression of the cluster gene cppig2 was examined. It showed markedly reduced expression levels 14 and 21 dpi in $\Delta$ cpnox 2 compared with the wild type (Fig. 5B), a result that could explain the white color of the pseudosclerotia produced by the mutant.

\section{Interaction studies.}

To gather information about the composition of the Nox complex in $C$. purpurea, a yeast two-hybrid assay was performed but, because CpNox1 and CpNox 2 as well as CpPls1 are membrane proteins, these components could not be checked with this nucleus-based method. In contrast, the regulatory protein CpNoxR is cytosolic (discussed below) and, therefore, its possible connection to small GTPases (especially Rac, which is a standard component of the phagocytic Nox complex) and related factors were investigated in this system. The small GTPases CpRac and CpCdc42 have been shown to affect polarity and pathogenicity in C. purpurea (Rolke and Tudzynski 2008; Scheffer et al. 2005). Interactions of CpNoxR with both GTPases, as well as with the scaffold protein CpBem1, were tested by fusing them to either the activation or the DNA-binding domain of the Gal4 transcription factor. GTP-locked (G14V) and GDP-locked (T22N) forms of CpRac were included in the assay because the activation state of $\mathrm{CpRac}$ has been shown to have an influence on interaction patterns with the p21-activated kinase CpCla4 (Rolke and Tudzynski 2008). The yeast strain pJ69-4A was co-transformed with the indicated plasmid combinations (Supplementary Table S2).

After transformation, all yeast strains grew equally on control medium without leucine and tryptophan (Fig. 6) whereas, on selective medium, CpNoxR showed a clear interaction with the small GTPase CpRac which was even enhanced with dominant active CpRacG14V. In contrast, no interaction could be observed with dominant negative CpRacT22N, indicating a strong influence of the GDP/GTP loading status of CpRac on the interaction patterns. Interaction of CpNoxR with neither the small GTPase CpCdc42 nor its GDP/GTP-locked forms CpCdc42G14V and CpCdc42T22N was detectable, although the two GTPases $\mathrm{CpCdc} 42$ and $\mathrm{CpRac}$ are structurally highly conserved. An interaction was observed between CpNoxR and the scaffold protein CpBem1, confirming observations in the related endophyte $E$. festucae (Takemoto et al. 2011) that components of the GTPase pathway are associated with the Nox complex.

CpNoxR also interacted with itself in the assay, indicating a possible homodimerization.

\section{Localization studies.}

mCherry fusions of CpNox1, CpNox2, and CpNoxR, as well as a green fluorescent protein (GFP) fusion of CpPls1, were used to study localization of these proteins in hyphae of the wild-type Cp20.1 (Fig. 7). The GFP fusion protein of CpPls1 clearly localized to the plasma membrane and to the endoplas-

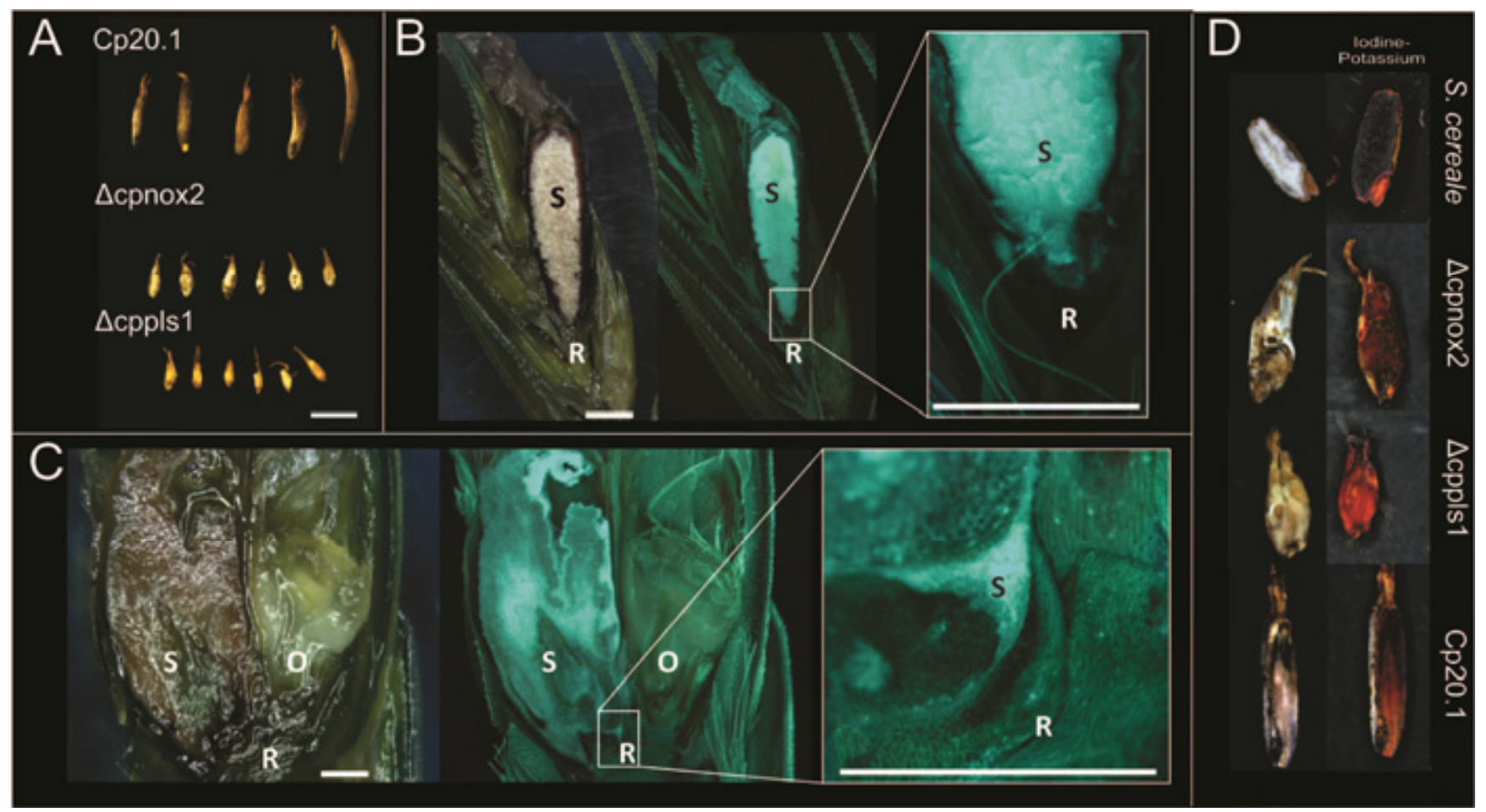

Fig. 3. Microscopic analysis of wild-type and mutant sclerotia. A, Comparison of sclerotia collected after in planta infection assays for the deletion strains $\Delta$ cpnox 2 and $\Delta$ cppls1 and wild-type Cp20.1. B, Cross sections of aniline-blue-stained sclerotium and surrounding in planta tissue after completed infection with wild-type Cp20.1 observed by light microscopy (left) and fluorescence microscopy (right); of special interest is the obviously noncolonized rachilla beneath the sclerotial tissue formed by the wild type (enlargement) (S: sclerotium; R: rachilla). C, Cross sections of aniline-blue-stained florets infected with $\Delta$ cpnox2 examined by light microscopy (left) and fluorescence microscopy (right) (S: sclerotial tissue; R: rachilla; O: ovary). The fluorescence clearly indicates the restriction of growth of $\Delta$ cpnox 2 to the primordial ovarian tissue because no staining can be detected within or underneath the rachilla of the infected plant material. The staining also indicates that the pseudosclerotial tissue produced by $\Delta$ cpnox 2 is fungal material. Bars $=5 \mathrm{~mm}$. D, Halved sclerotia of wild-type Cp20.1 and pseudosclerotia of the deletion strains $\Delta$ cpnox2 and $\Delta$ cppls1 collected from in planta infected rye (left). Starch analysis was performed by iodine-potassium staining in cross sections of wild-type and mutant sclerotia as well as in uninfected seed from Secale cereale as a positive control (right). Iodine-potassium reacts with starch and produces a dark blue color. Starch could be detected only in S. cereale but in neither deletion strain probe, implying that all nonripened sclerotia consist of fungal material. 
matic reticulum (ER). This localization could be confirmed by use of the ER-Tracker Blue-White DPX. The construct was shown to be functional because it was able to complement the $\Delta$ cppls1 mutant phenotype. The mCherry fusions of CpNox1 and CpNox 2 appeared to be located mainly in the ER of C. purpurea. This localization was also confirmed by using ERTracker Blue-White DPX and staining with Hoechst 33342, respectively. The fusion protein of $\mathrm{CpNox} 2$ also showed a general tendency to accumulate in vacuoles, a result that may be an effect of the overexpression construct resulting in an excess of degradation products (data not shown). Hyphae of wild-type strains expressing the CpNox $1:$ mCherry construct displayed a slight hyper-branching phenotype which, again, might be due to overexpression of the fusion protein (Fig. 7B). The CpNoxR:: mCherry fusion protein was located equally distributed in the cytoplasm as well as within microscopic mobile particles within the fungal hyphae (data not shown).

\section{DISCUSSION}

We had shown previously that the $\Delta$ cpnox 1 mutant of $C$. purpurea is impaired in host tissue colonization and sclerotial formation (Giesbert et al. 2008). In this study, we showed that the second Nox enzyme CpNox 2 is also important for the development of $C$. purpurea during pathogenesis but, unlike CpNox1, CpNox2 is not involved in the early infection stages. In $\Delta$ cpnox2-infected floral tissue, an unusual accumulation of large quantities of honeydew was observed in late stages, starting approximately $7 \mathrm{dpi}$. Such a phenotype has not been observed in the wild type or in any mutant studied thus far. Because honeydew consists of plant-derived phloem sap, the deletion mutant causes increased costs on the host side of the interaction. Furthermore, this sweet exudate contains fungal conidia and assists the dispersal of the pathogen. An overproduction of honeydew, as observed for $\Delta$ cpnox 2 , could substantially increase infection rates within one season. However, although the consequences of the infection with the $\Delta$ cpnox 2 mutant appear to be quite severe, the explanation for the honeydew accumulation may be rather simple, because the analyses show that the mutant lacks the ability to initiate sclerotia formation and, therefore, remains within the sphacelial (honeydew-producing) stage. In accordance with this hypothesis, the real-time data indicate that there is an induction of cpnox 2 expression in the wild type in the later stage (10 dpi) of an
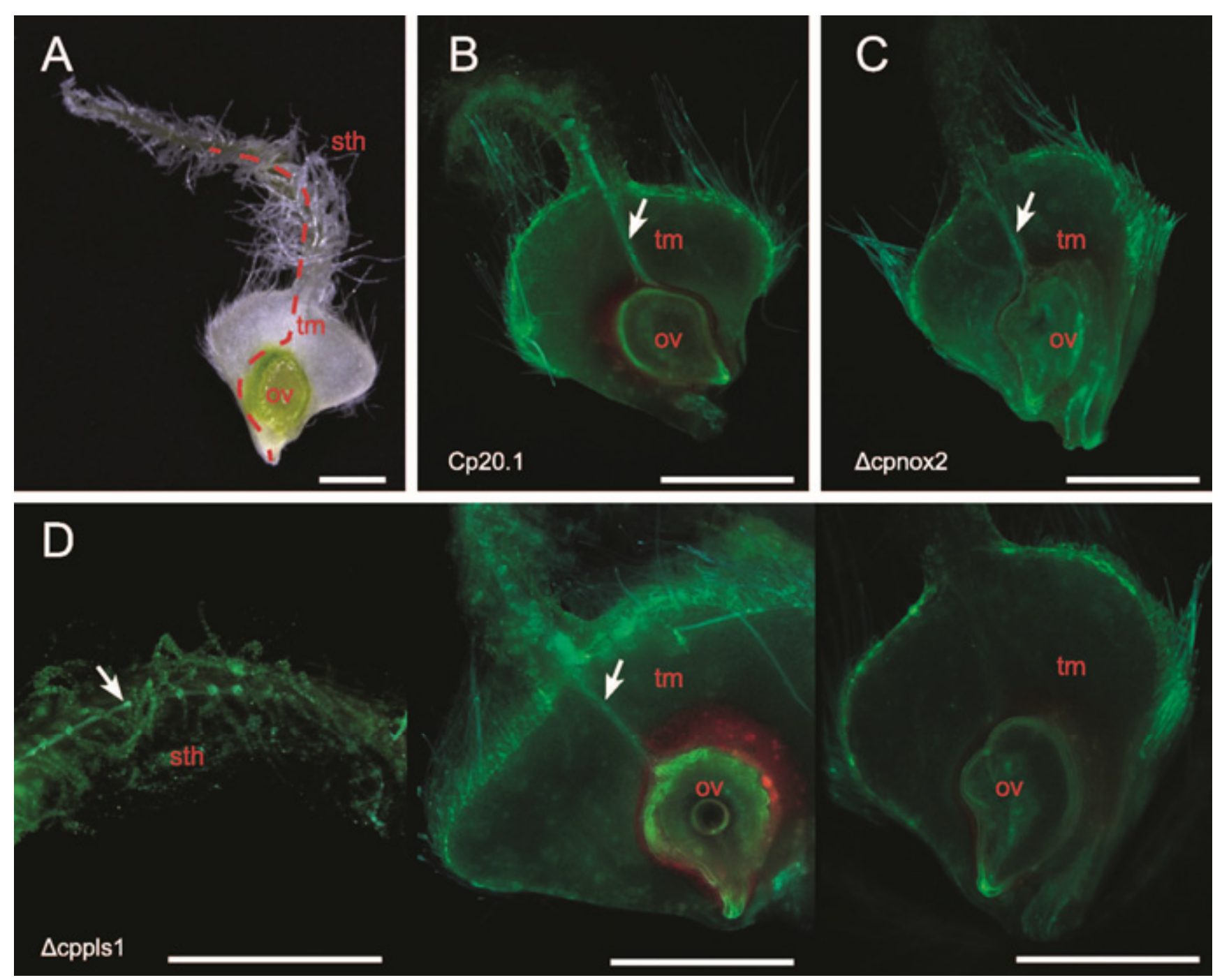

Fig. 4. In vitro cultivated rye florets infected with deletion strains $\Delta$ cpnox $2, \Delta$ cppls1, and wild-type $C p 20.1$. Isolated rye ovaries were cultivated in vitro on Hoagland agar plates and inoculated with the indicated strains. After 5 days, cross sections of the ovaries were stained with aniline blue (emitting green fluorescence), allowing the detection of fungal hyphae within the plant tissue by fluorescence microscopy. A, Schematic overview of the infection route of Claviceps purpurea. B and C, Fungal hyphae (indicated by arrows) could be monitored in all ovaries inoculated with the wild type and the $\Delta$ cpnox 2 mutant whereas D, not all ovaries inoculated with $\Delta$ cppls1 were colonized to the same extent and, therefore, showed different stages of fungal colonization. Bars $=5 \mathrm{~mm}$; sth: stigmatic hairs, tm: transmitting tissue, ov: ovule. 
infection during sclerotial development and only minor expression during the early phase (Fig. 5A). Expression of sclerotiaspecific genes, exemplified by the putative pigment cluster gene cppig2, are not induced in the pseudosclerotia of $\Delta$ cpnox 2 , confirming the above hypothesis. Interestingly, the immature sclerotia that are rarely produced by the cpnox $1 \mathrm{mu}-$ tant are similar in appearance, indicating a defect in the same morphological process in both cpnox deletion mutants at this growth stage. However, in the rare cases where $\Delta$ cpnox 1 (and also $\Delta$ cppls1) reaches the base of the ovary, it produces only a small amount of honeydew. Honeydew production is thought to be accompanied by the secretion of a $\beta-1,3$-glucanase in $C$. purpurea to degrade phloem callose, thus enabling the phloem transport into the fungal sphacelium (Brockmann et al. 1992). Therefore, an increased production of this protein could lead to an overproduction of honeydew. However, this process could not be demonstrated in real-time expression analyses of $\Delta$ cpnox 2 (data not shown). Therefore, the only explanation for this phenotypical difference thus far established is that the amount of hyphae reaching the rachilla is reduced in the $\Delta$ cpnox1 strain, whereas $\Delta$ cpnox 2 was shown to grow like the wild type at this growth stage. However, if only the successful $\Delta$ cpnox1 infections are taken into account, the formation of pseudosclerotia is comparable in both mutants. In general, it is well known that oxidative stress can be an inducing factor for biogenesis of sclerotia in fungi (Georgiou et al. 2006), and an inhibiting effect of antioxidant hydroxyl radical scavengers on sclerotia formation in Sclerotinia sclerotiorum and Rhizoctonia solani has been described (Georgiou et al. 2000), but the precise mechanism is not understood. Also, B. cinerea and $S$. sclerotiorum $\Delta$ nox mutants are impaired in sclerotia formation (Kim et al. 2011; Segmüller et al. 2008). Therefore, the local production of ROS via the active Nox complex might induce signaling cascades necessary for the morphological switch to production of sclerotia. In contrast to many other fungi, formation of sclerotia in $C$. purpurea has been observed exclusively in planta. Previous attempts to analyze external factors that

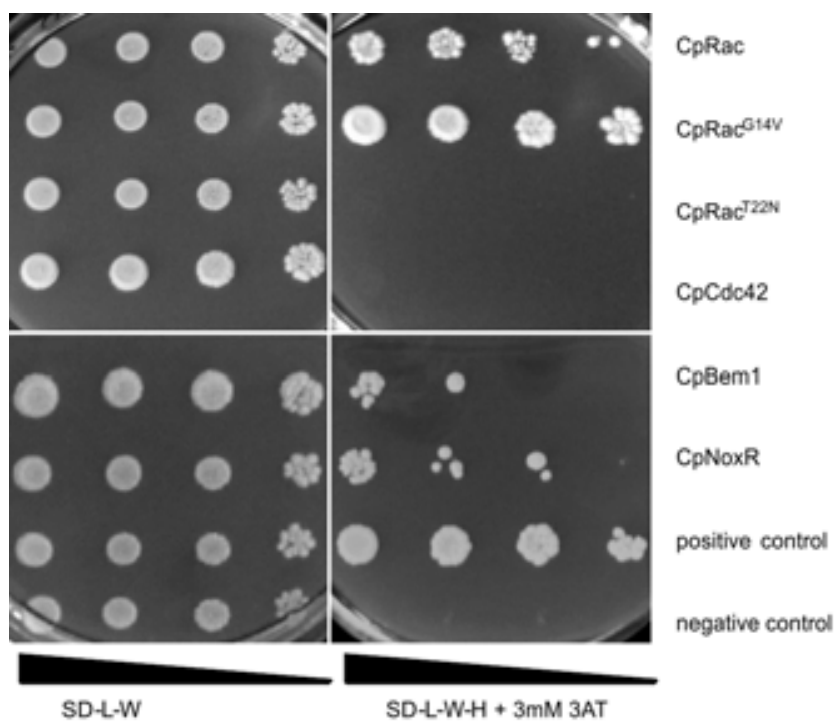

Fig. 6. Yeast two-hybrid assay. Derivatives of yeast strain pJ69-4A containing the indicated vectors in combination with the pAD-Gal4-2.1CpNoxR vector, starved in $1 \mathrm{M}$ sorbitol for $5 \mathrm{~h}$, and dropped onto selective media: synthetic defined medium without leucine and tryptophan (SD-LW) was used to select for expression of both constructs and SD without leucine, tryptophan, and histidine containing 3AT (SD-L-W-H+3AT) for selection of interacting combinations. Positive control: CpCla4/ $\mathrm{CpRac}^{\mathrm{G} 14 \mathrm{~V}}$, negative control: empty BD/AD vectors. Dropped strain dilutions were $1,1: 10,1: 100$, and 1:1000.
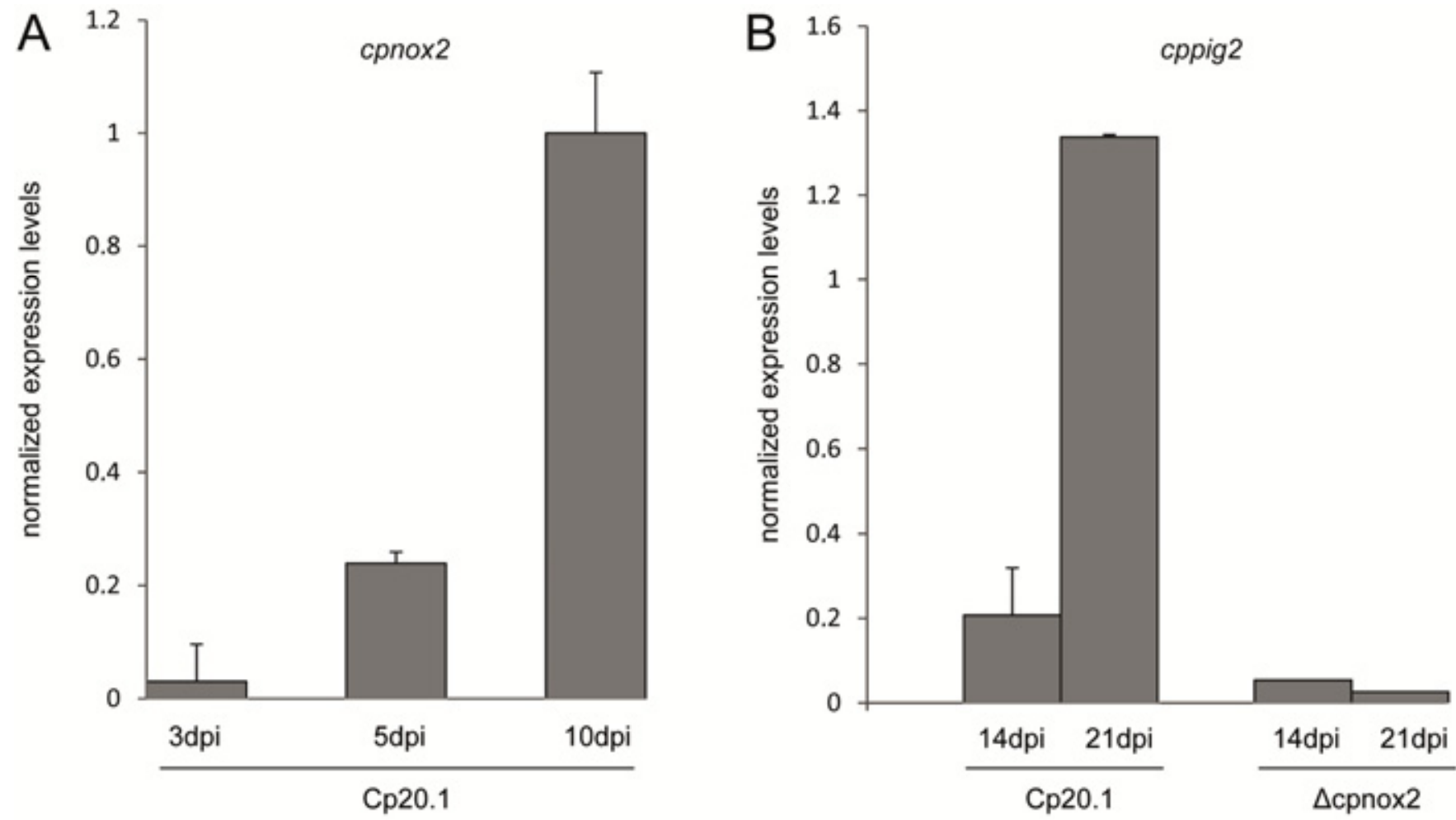

Fig. 5. Gene expression in planta. A, Expression levels of cpnox 2 in the wild-type Cp20.1 during infection was determined by quantitative reverse-transcription-polymerase chain reaction (qRT-PCR) and normalized to three fungal housekeeping genes ( $\beta$-tubulin, $\gamma$-actin, and glyceraldehyde-3-phosphate dehydrogenase $[$ gpd]). Expression strongly increased towards the 10th day postinoculation. B, Expression levels of cppig2 in the wild-type Cp20.1 and $\Delta$ cpnox 2 during infection were determined by qRT-PCR and normalized to three housekeeping genes ( $\beta$-tubulin, $\gamma$-actin, and gpd). Whereas the expression of $c p p i g 2$ strongly increases in the wild type at day 21 postinfection, this increase in expression is completely abolished in the $\Delta$ cpnox 2 mutant. 
may influence sclerotia biogenesis, such as $\mathrm{pH}$ and nitrogen source, only led to the development of sclerotia-like hyphae in axenic cultures (Mantle and Nisbet 1976). It is most likely that the fungus depends on plant-derived triggers or the organ structure of the flower for this process. Moreover, it is speculated that the Ergot alkaloids which are exclusively formed in sclerotia in the field protect the infected plant from grazing animals, indicating that the infection with the Ergot fungus can also be beneficial for the host plant (Haarmann et al. 2009). Generally, sclerotia production is essential for the survival of $C$. purpurea during periods in which host plants do not flower (especially in the winter) and, therefore, are not receptive for an infection. They also form the basic structure for the sexual development of the fungus as sclerotia germinate and differentiate stroma heads which contain the perithecia of the fungus (Alderman 2003). Taken together, sclerotia formation plays a

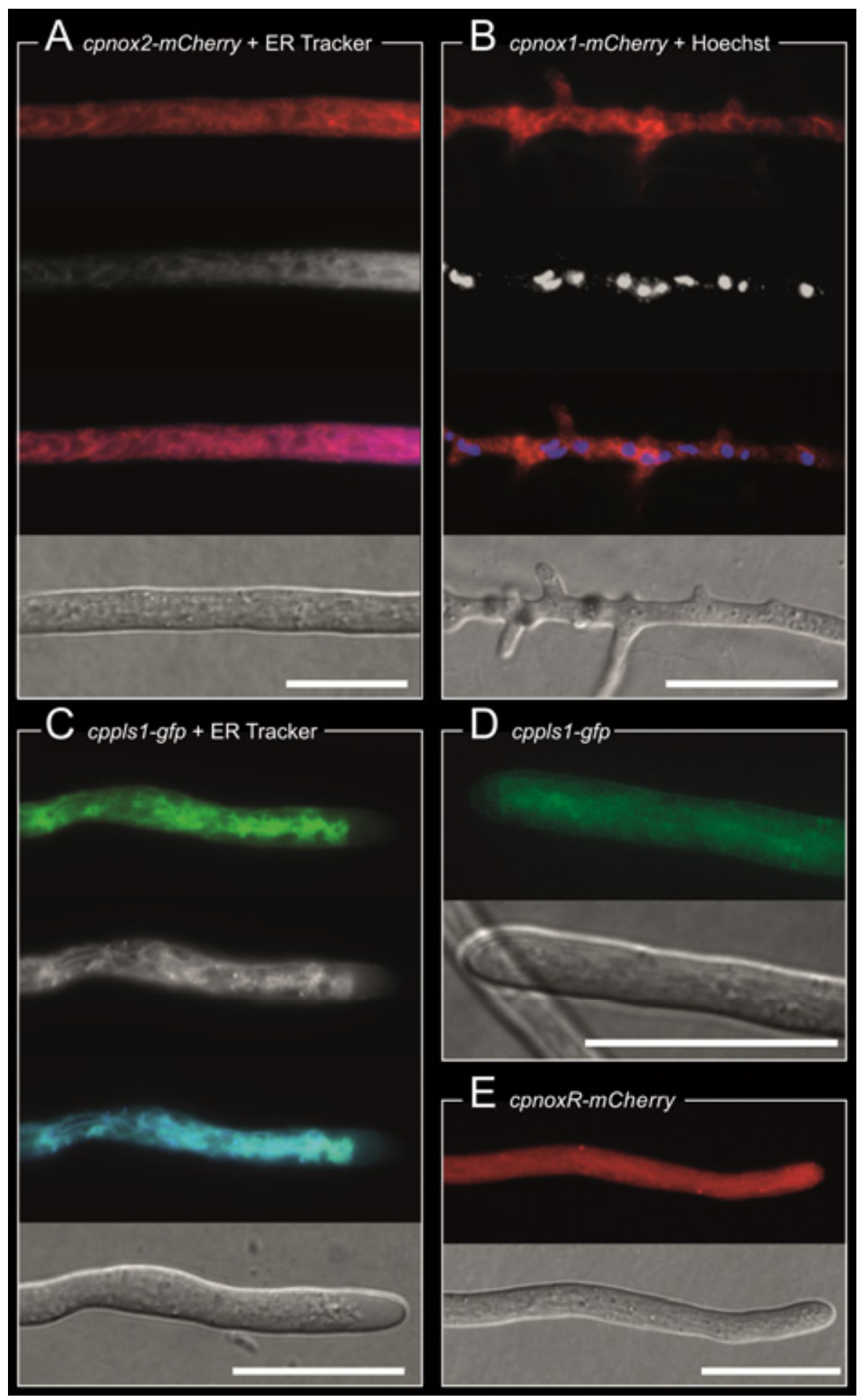

Fig. 7. In vivo localization of reporter gene fusion proteins of $\mathrm{CpNox} 1, \mathrm{CpNox} 2, \mathrm{CpNoxR}$, and CpPls1. Localization of fusion proteins of $\mathrm{CpNox} 1$, $\mathrm{CpNox} 2$, CpPls1, and CpNoxR in hyphae of Cp20.1 in axenic culture. A, CpNox2-mCherry localizes to the endoplasmatic reticulum (ER) of fungal hyphae (top to bottom: fusion proteins, ER-Tracker, overlay, and differential interfence contrast [DIC]). B, CpNox1-mCherry localizes to the ER of fungal hyphae (top to bottom: fusion proteins, Hoechst, overlay, and DIC). CpPls1-gfp also localizes to C, the ER (top to bottom: fusion proteins, ER-Tracker, overlay, and DIC) and $\mathbf{D}$, the plasma membrane. E, CpNoxR-mCherry localizes to the cytoplasm and accumulates in mobile particles. Bars $=20 \mu \mathrm{m}$. 
central role in the life style of $C$. purpurea because it enforces the sexual life cycle of the fungus and, at the same time, prevents the host plant from excessive (assimilate) costs. Therefore, this Nox-dependent process is fundamental to the balance of the biotrophic interaction with its host plant.

Apart from sclerotia formation, the main defects observed in noxB or nox 2 deletion mutants in different fungi affect ascospore germination ( $P$. anserina and $N$. crassa) and formation of functional appressoria (B. cinerea and M. oryzae) (CanoDominguez et al. 2008; Malagnac et al. 2004; Ryder et al. 2013; Segmüller et al. 2008). C. purpurea does not form appressoria and, because ripe sclerotia are required to fulfill its sexual life cycle, neither the formation of perithecia nor ascospore germination could be analyzed in $\Delta$ cpnox 2 . However, Lambou and associates (2008) have already postulated that the different morphogenetic processes "ascospore germination" in $P$. anserina and "penetration peg formation" in the appressoria maturation of $M$. oryzae rely on the same molecular machinery (including Nox2 and Pls1) because they show striking similarities in morphological and physiological processes. Both structures are heavily pigmented with melanin in the outer cortex, require polarity establishment for their function, and include the catabolism of lipids. There are some striking parallels here with the induction of sclerotia in $C$. purpurea. The sclerotia of C. purpurea are also heavily pigmented structures, though they contain the Ergot-characteristic purple pigments instead of melanin (Franck 1969). Furthermore, microscopical studies show that the sclerotial tissue originates from a generative zone that is built up at the end of the sphacelial stage. It consists of highly polarized cylindrical cells, organized in a palisade formation (Luttrell 1980). The underlying mechanism leading to this polarized growth has yet to be elucidated but the involvement of polarity complex components is most likely. Finally, sclerotial hyphae of $C$. purpurea are packed with globules, containing high amounts of lipids (up to $30 \%$ dry weight), mainly triglycerides consisting of ricinoleate. The lipids are stored within the sclerotia and are mobilized during fruiting body formation (Corbett et al. 1975). Similarly, an accumulation of lipid bodies in the nascent appressorium of $M$. oryzae has been described and a triacylglycerol lipase activity is induced during appressoria maturation (Thines et al. 2000).

In different fungi (B. cinerea, $M$. oryzae, and P. anserina), a close connection of Nox 2 or NoxB to the tetraspanin Pls1 has been corroborated because deletion mutants of pls1 and nox 2 in the analyzed fungi showed similar phenotypes (Lambou et al. 2008; Siegmund et al. 2013; Ryder et al. 2013). In C. purpurea, the situation is clearly more complex. In contrast to CpNox2, CpPls1 is already required for the colonization of the host tissue in the early stages of an infection because detailed analyses of $\Delta$ cppls 1 showed a retarded colonization process in this mutant. A similar phenotype was described for $\Delta$ bcpls1 of $B$. cinerea (B05.10) because this mutant seemed to be retarded in lesion formation on French bean leaves (Siegmund et al. 2013). Plsl deletion mutants of M. oryzae, Colletotrichum lindemuthianum, and a second B. cinerea isolate (T4) are even nonpathogenic (Clergeot et al. 2001; Gourgues et al. 2004; Veneault-Fourrey et al. 2005).The mutants of the different plant-pathogenic fungi all have in common that they are not able to colonize the plant tissue in a wild-type-like manner. This has been due to either a decreased penetration efficiency or the formation of nonfunctional appressoria and, therefore, to the loss of their penetration ability.

Because Claviceps purpurea does not form appressoria to penetrate the plant, this explanation does not apply; however, an effect of CpPls1 on the penetration process of $C$. purpurea cannot be excluded. In axenic culture, conidia of $C$. purpurea $\Delta$ cppls1 show wild-type-like germination rates, and micro- scopical analyses as well as pathogenicity assays show that it is able to penetrate the plant but afterward fails to colonize it. As a result, the mutant is only rarely able to reach the base of the ovary to gain access to the phloem of the plant. Accordingly, the formation of honeydew is drastically reduced and only immature pseudosclerotia are formed. Therefore, C. purpurea is the first fungus known thus far in which the $\Delta$ pls1 phenotype is more similar to the $\Delta$ nox 1 than to the $\Delta$ nox2 phenotype. Nevertheless, all three deletion mutants have overlapping phenotypes in the sclerotial stage and, because the $\Delta$ cpnox 1 phenotype in $C$. purpurea is probably epistatic to the $\Delta$ cpnox 2 phenotype, a connection of $\mathrm{CpPls} 1$ to both $\mathrm{CpNox}$ subunits cannot be excluded. Thus far, no direct physical interaction has been reported in fungi for any Nox protein with Pls1. In mammals, tetraspanins have been shown to form a "tetraspanin web" within membranes which consists of lateral associations of multiple proteins organized in clusters (Levy and Shoham 2005). Most commonly, tetraspanins interact (apart from homo-dimerization) with other membrane proteins such as integrins or members of the immunoglobulin superfamily (Hemler 2003). Interactions within the web are very complex and dynamic. They are subdivided into three levels: primary (direct) interactions, secondary interactions (typically tetraspanin hetero-dimers, building multi-component complexes), and tertiary interactions (defined as those tetraspanin interactions that are disrupted in detergents). Together, these complexes build up a tetraspanin-enriched microdomain which functions in different signaling events (Hemler 2005). Therefore, it might also be possible that CpPls1 produces a tetraspanin web in $C$. purpurea which serves as a basis for the formation of both Nox complexes regardless of a direct interaction.

Within this study, fusion proteins have, for the first time, successfully been used to identify the intracellular localization of proteins in $C$. purpurea. Fusion proteins of CpNox1, CpNox2, and CpPls1 support the proposed hypothesis because all three are enriched in the same intracellular compartment. Co-staining with the ER-Tracker Blue-White DPX clearly identified the compartment to be the fungal ER. This localization pattern was rather surprising because none of the protein sequences contains an obvious ER retention signal. Therefore, one reason might be a mislocalization of the proteins. However, this is unlikely because the GFP::CpPls1 fusion protein has been shown to complement $\Delta$ cppls1. Moreover, non-ERretention signal-based mechanisms have been shown to lead to sufficient ER retention of different proteins (Bretscher and Munro 1993; Däubner et al. 2010). Whether the Nox complexes function inside the ER or are translocated to the plasma membrane under specific conditions remains to be elucidated. It is noteworthy that experimental evidence for the presence of NADPH oxidases in the ER membrane was provided for mammalian Nox1, Nox2, and Nox4 proteins and the NoxA and NoxB proteins from $B$. cinerea and Saccharomyces cerevisiae Yno1 (Ambasta et al. 2004; Petry et al. 2006; Rinnerthaler et al. 2012; Siegmund et al. 2013). Thus far, only for Nox4 has a direct influence on the redox status of this compartment been established ( $\mathrm{Wu}$ et al. 2010). The putative regulatory mechanisms of ER-localized ROS are manifold and could, for example, generally influence protein folding or modifications. On the other hand, tightly regulated protein secretion from the ER was shown to influence morphological processes such as septum formation and budding in S. cerevisiae (Chin et al. 2012; Zhang et al. 2011). Because both Nox subunits of $C$. purpurea mainly function during pathogenesis, a similar translocation might not be observed in the (analyzed) axenic conditions but only during growth in planta. However, the analysis of fusion proteins in $C$. purpurea during in planta growth is challenging and has not been successful. In M. oryzae, a transport of Nox2 
in intracellular vesicles has been described during the Nox-dependent appressorium-ripening, with the ultimate function at the appressorium cortex. Similarly, the regulatory subunit NoxR has been observed within vesicles and the cytoplasm in $M$. oryzae and $B$. cinerea, whereas it has been shown to accumulate at the hyphal tips in the closely related E. festucae. Here, we show a localization of CpNoxR::mCherry throughout the cytoplasm as well as in microscopic mobile particles within fungal hyphae. These results suggest either transport of the protein in tiny vesicles or aggregations of (inactive) CpNoxR homo-dimers. The latter explanation is strengthened by the yeast two-hybrid results, which indicate interaction of CpNoxR with itself. Additionally, NoxR homo-dimers have also been shown to be dispersed within the cytoplasm of $E$. festucae in bimolecular fluorescence complementation assays (Takemoto et al. 2011). Assuming an interaction of CpNoxR with at least one of the CpNox enzymes, the logical consequence of the cytosolic localization of CpNoxR is an outward orientation of CpNox from the ER or, again, the transport of CpNox to the plasma membrane under Nox-inducing conditions.

Within the proposed transport model, Pls1 could have an important role for the ER exit of the Nox enzymes. The tetraspanins UPIa and UPIb (from a specialized urinary tract epithelium) form hetero-dimers with their respective non-tetraspanin partners UPII/ UPIII in the ER. More importantly, the exit of the non-tetraspanin proteins is totally dependent on this interaction, whereas the tetraspanin UPIb is able to leave the ER and move to the plasma membrane without the formation of the hetero-dimer (Levy and Shoham 2005; Tu et al. 2002). This is in agreement with the plasma membrane association (additional to the ER) of CpPls1 which was observed in $C$. purpurea.

Recently, it has become clear that fungal Nox enzymes and Pls1, as in the mammalian system, are involved in F-actindependent cytoskeletal reorganization in $M$. oryzae and $S$. cerevisiae (Rinnerthaler et al. 2012; Ryder et al. 2013; San Martin and Griendling 2010). A direct effect of the tetraspanins CD9 and CD82 on actin organization has also been established in mammals. The C-terminal tail of some tetraspanins (e.g., CD151) is thought to interact with cytosolic proteins that affect Rac signaling which, in turn, leads to changes in actin dynamics (Hemler 2005). Although hyphae of $\Delta$ cpnox 1 and $\Delta$ cppls1 do not show drastic morphological defects in axenic culture, an impaired cytoskeletal organization in planta may be one reason for the disturbed colonization process. Furthermore, it is tempting to speculate that the formation of the cells of the generative zone during formation of sclerotia requires a functional mechanism to establish hyphal polarity. The hypothesized influence of the Nox complexes on the fungal cytoskeleton is strengthened by our results of protein-protein interaction of CpNoxR with polarity complex components. CpNoxR clearly interacts with the putative scaffold protein CpBem1, which is involved in polarity establishment of different organisms and is suggested to be the functional ortholog of $\mathrm{p} 47^{\text {phox }}$ and $\mathrm{p} 40^{\text {phox }}$ in the Nox complexes of fungi (Kawahara and Lambeth 2007). An amino acid sequence analysis of CpBem1 and CpNoxR identifies a type II and a type I/II type of PB1 domain which are able to interact via salt bridges (Sumimoto et al. 2007). However, in the closely related E. festucae, an interaction of the isolated PB1 domains could not be proven, whereas the full-length proteins were shown to interact in vitro as well as in vivo (bimolecular fluorescence complementation assays $[\mathrm{BiFC}]$ ), indicating that further motifs are involved in this interaction. A direct interaction of CpNoxR with the small GTPase CpRac could also be demonstrated. This emphasizes the putative influence of the Nox complex on the cytoskeleton, because the cprac deletion mutant of $C$. purpurea is markedly impaired in polarization (Rolke and Tudzynski 2008). A second small GTPase, CpCdc42 (sharing 60\% amino acid sequence identity with $\mathrm{CpRac}$ ), did not show any interaction, emphasizing the specificity of the CpNoxR-CpRac interaction. Moreover, the observation that, in the yeast two-hybrid experiment, the dominant active GTP-bound form of $\mathrm{CpRac}$ interacts more strongly with CpNoxR than the wild-type CpRac, while the dominant negative CpRac mutant fails to interact, strongly suggests that the active form of this small GTPase is part of the Nox complex. As outlined above, the Nox complex assembly in $C$. purpurea seems to be induced mainly in planta. The ultimate evidence for the composition of the Nox complex and the interactions between its components requires BiFC assays, which are technically challenging in the C. purpurea-rye interaction.

Taken together, our results demonstrate that the second catalytical Nox subunit CpNox2, as well as the tetraspanin CpPls1, are important for a balanced host-pathogen interaction of $C$. purpurea with its host plant. Unexpectedly, $\Delta$ cppls1 mainly resembles the $\Delta$ cpnox 1 instead of the $\Delta$ cpnox 2 phenotype, with overlapping features of all three mutants in sclerotia formation. Most notably, the infection with the $\Delta$ cpnox 2 strain leads to increased disease symptoms which can partly be explained by an impaired development in planta. In the closely related fungus $E$. festucae, deletion of noxA renders the former endophytic fungus a pathogen. In normal infections, NoxA seems to control biomass formation of the fungus to prevent the induction of disease symptoms in the plant (Takemoto et al. 2007). The situation seems to be similar in $C$. purpurea. Here, CpNox 2 induction attenuates disease symptoms via the morphological switch to sclerotia formation and subsequent unknown processes. This phenomenon highlights the molecular adaption of the highly specialized biotrophic lifestyle of $C$. purpurea to its host plant.

\section{MATERIALS AND METHODS}

\section{Strains, media and growth conditions.}

The wild-type $C$. purpurea strain used as the recipient strain for gene replacement and reporter gene analyses was $\mathrm{Cp} 20.1$, a putative haploid derivative of standard field isolate T5 (Fr.:Fr.) Tul., isolated from rye (Secale cereale L.; Hohenheim, Germany), and obtained by benomyl treatment (Hüsgen et al. 1999). For harvesting of conidia and DNA isolation, mycelia were cultivated on Mantle agar (15 g/liter of agar) with sucrose at $100 \mathrm{~g} /$ liter (Mantle and Nisbet 1976) at $26^{\circ} \mathrm{C}$ for 12 to 14 days. In addition to the transformants created for this study, the deletion mutant $\Delta$ cpnox1 (Giesbert et al. 2008) was included in some analyses.

For localization studies, the strains Cp20.1-nox1::mCherry, Cp20.1-nox2::mCherry, Cp20.1-noxR::mCherry, and Cp20.1pls $1:$ GFP were generated, using the respective expression vector constructs.

To test oxidative stress reactions, Mantle agar was supplemented with menadione (concentrations of 0.05 to $0.45 \mathrm{mM}$ ). For each concentration, six agar plates were inoculated with the different mutants and the wild-type Cp20.1 as a control and grown for 15 days. Additionally, all strains were grown on Mantle agar without menadione.

Escherichia coli TOP10F' (Invitrogen, Darmstadt, Germany) was grown on LB media (Bertani 1951) supplied with appropriate antibiotics and used for all subcloning experiments.

For vector construction according to the yeast recombinational method, yeast strains SMY3 (Cardenas et al. 1994; Harper et al. 1993) and FMY834 (Winston et al. 1995) were used whereas, for yeast two-hybrid experiments, yeast strain pJ69- 
4A (James et al. 1996) was used. All yeast strains were grown on yeast extract peptone dextrose media for propagation or on synthetic defined (SD) media lacking specific amino acids for selection.

\section{Bioinformatical analysis.}

DNA sequencing was carried out as described by Moore and associates (2002). Protein and DNA sequence alignment, editing, and organization were done with DNA Star (Madison, WI, U.S.A.). For further sequence analysis, BLAST at National Center for Biotechnology Information, Bethesda, MD, U.S.A. (Altschul et al. 1997) and special domain search programs, such as prediction server TMHMM2.0 (Sonnhammer et al. 1998) and CDD server (Marchler-Bauer et al. 2011), were used.

\section{Statistical analysis.}

Independent comparisons of the mutant strains with the wild-type Cp20.1 by two-sample $t$ tests were performed in Excel (Microsoft, Seattle).

\section{Nucleic acid analysis.}

Standard recombinational DNA methods were performed according to Sambrook and associates (1989) and Ausubel and associates (1987). Genomic DNA from C. purpurea was prepared from lyophilized mycelium according to Cenis (1992). For Southern blot analysis, probes of 5 to $10 \mu \mathrm{g}$ of digested genomic DNA were separated electrophoretically in $1 \%$ agarose gels with salt-free buffer (Sambrook et al. 1989), blotted onto positively charged nylon filters (Hybond-N+; Amersham, Braunschweig, Germany), and hybridized to radioactively labeled DNA probes in Denhardt's hybridization solution (Sambrook et al. 1989). Filters were washed for $10 \mathrm{~min}$ in $2 \times$ $\mathrm{SSC}(1 \times \mathrm{SSC}$ is $0.15 \mathrm{M} \mathrm{NaCl}$ plus $0.015 \mathrm{M}$ sodium citrate) and $0.1 \%$ sodium dodecyl sulfate (SDS) and for $10 \mathrm{~min}$ in $1 \times$ SSC and $0.1 \%$ SDS. Hybridization and washing of the filters were carried out at $65^{\circ} \mathrm{C}$. PCR was performed as described by Sambrook and colleagues (1989) using the BioTherm Polymerase (GeneCraft GmbH, Lüdinghausen, Germany). All primers were synthesized by MWG-Biotech (München, Germany). The amplification products were cloned with the pCR 2.1 TOPOCloning Kit (Invitrogen, Carlsbad, CA, U.S.A.). PCR amplifications for fusion proteins or interaction assay vectors were performed using the proof reading Phusion polymerase (Finnzymes, Espoo, Finland).

\section{Expression studies and quantitative RT-PCR.}

Total RNA of infected in planta material was isolated using the RNeasy Midi Kit from Qiagen (Hilden, Germany).

Real-time qPCR reactions were performed with the Bio-Rad iQ SYBR Green Supermix and the iCycler Thermal Cycler (Bio-Rad, Hercules, CA, U.S.A.). Programming, data collection, and analyses were performed with the iCycler iQ Real-Time Detection System Software (version 3.0; Bio-Rad). Expression of cpnox2 was detected by the primers RT_nox2_fw_2 and RT_Nox2_rev_2. Expression of cppls1 was detected by the primers RT_Pls1_fw and RT_Pls1_rev. To analyze expression of the putative pigment cluster gene cppig2, the primers $\mathrm{RTq}_{-}$ LN4_F and RTq_LN4_R were used. The expression of all analyzed genes was normalized to the expression of housekeeping genes encoding for $\beta$-tubulin (CCE34429.1), $\gamma$-actin (AEI72275.1), and gpd (X73282.1) (Giesbert et al. 2008). The following primers were used, respectively: Tub uni and Tub rev, Actin uni and Actin rev, and Gpd uni and Gpd rev. After performance of qRT-PCR, products were monitored by melt curve analyses and gel electrophoresis. As a negative control, cDNA from noninfected rye ovaries was used.
Generation of replacement and complementation vectors.

For the construction of the gene replacement vector $\mathrm{p} \Delta$ cpnox2, primers NotI-7.1for and XbaI-7.1rev were used to amplify a 1,213-bp fragment of the cpnox 2 genomic region containing part of the promoter and coding region of cpnox 2 . The primers contained the artificial restriction sites Not I and $X b a \mathrm{I}$, respectively. The obtained PCR fragment was cloned into the pCR2.1 TOPO vector (Invitrogen) for sequencing and subsequently excised with NotI and XbaI. The resulting fragment was introduced into the NotI and $X b a I$ restricted hygromycin resistance cassette containing plasmid pAN7-1UM (Müller et al. 1997). Primers EcoRV7.1-dnox2No2 and HindIII-7.1 rev containing artificial EcoRV and HindIII sites amplified a 983-bp fragment which was cloned into the pCR 2.1 TOPO vector for sequencing. After excision with EcoRV and HindIII, the fragment was cloned into the EcoRV and HindIII restricted vector pAN7-1UM which already contained the 5' flank. Between primers XbaI-7.1rev and EcoRV7.1dnox2No2, a 196-bp genomic region encodes the NADPH binding domain, which was replaced by the hygromycin resistance cassette in the vector $\mathrm{p} \Delta$ cpnox 2 . Digestion of $\mathrm{p} \Delta \mathrm{cpnox} 2$ with NotI and HindIII released a 6,093-bp fragment, which was used to transform the $C$. purpurea wild-type strain 20.1 .

To obtain a full-length clone of cpnox 2 for complementation of the mutant strain $\Delta$ cpnox2, the primers Cpnox2_comp_hin_ NCR and Cpnox2_comp_rück_NCR were used to amplify a 2,960-bp fragment including the native promoter and terminator region of cpnox2. The fragment was cloned into the pCR 2.1 TOPO vector. The complementation fragment was verified by sequencing. Subsequently, the complementation vector cpnox2_comp was obtained by cloning the EcoRI excised fragment into the corresponding restriction site of the vector pAN8-1UM (Müller et al. 1997), carrying a phleomycin resistance cassette. The obtained plasmid was used to transform the $C$. purpurea $\Delta$ cpnox 2 mutant strain.

The gene replacement fragment for cppls 1 was obtained via the yeast recombinational cloning method (Colot et al. 2006). Therefore, the flanking regions of cppls 1 were amplified with the following primers containing overlapping sequences toward the yeast shuttle-vector pRS426 or the phleomycin resistance cassette: 5FPls 1 and 5RPls1for the $5^{\prime}$ flank as well as 3FPls 1 and 3RPls1 for the $3^{\prime}$ flanking sequence. The PCR-products (975 and $978 \mathrm{bp}$ ), the linearized yeast shuttle vector pRS426 (Christianson et al. 1992), and the phleomycin resistance cassette (taken from pAN8-1UM; XhoI/XbaI, 2,378 bp) were transformed into yeast strain FMY834 for homologous recombination. DNA isolation of yeast cells was performed using the SpeedPrep yeast plasmid isolation kit (DualSystems, Schlieren, Switzerland). The DNA was subsequently recruited for a PCR with the primers 5FPls1 and 3RPls1, resulting in a 4,294-bp fragment, which was used to transform the $C$. purpurea wildtype strain 20.1 .

\section{Generation of fusion protein vectors.}

Vectors for expression of fusion proteins were constructed for in vivo localization studies of Cpnox1, Cpnox2, CpnoxR, and Cppls1. For Cpnox1 with primers Nox1_mCherry_overlap and Nox1_Ttub_overlap, a PCR fragment was amplified from wild-type DNA with Phusion polymerase and inserted into NotI-digested pNDH-OCT (Schumacher 2012) by yeast recombination. The Cpnox 2 fusion protein was constructed by recombination of NcoI-restricted vector pNDH-OCT (Schumacher 2012) with a 1.9-kb PCR fragment produced by primers Nox2_mCherry_fw and Nox2_mCherry_rev. For CpnoxR, primers NoxR_mCherry_fw and NoxR_mCherry_rev amplified a fragment which was then inserted into pNDH-OCT-restricted NotI (Schumacher 2012). Expression of these fusion proteins 
in Claviceps spp. should lead to mCherry fluorescence. For Cppls1 a GFP fusion protein vector was constructed, using PCR primers Pls1_Prom_fw and GFP_Pls1_Prom_rev (amplification of 1.9-kb promoter region), GFP_Pls1_rev and oGFPF (GFP amplification), and Pls1_GFP_fw and Pls1_Term_rev (amplification of cppls1 and terminator region) and vector pNAH-OGG (Schumacher 2012) after restriction with SpeI/ EcoRI.

\section{Fungal transformation.}

Protoplasts of $C$. purpurea generated with lysing enzymes from Trichoderma harzianum (Sigma-Aldrich, St. Louis) and Driselase (InterSpex, San Mateo, CA, U.S.A.) were transformed with $10 \mu \mathrm{g}$ of the deletion fragments for Cpnox 2 and Cppls1, respectively, as described by Jungehülsing and associates (1994). For selection, phleomycin was directly applied to the protoplasts to a final concentration of $33 \mu \mathrm{g} / \mathrm{ml}$ in modified BII medium ( $\mathrm{pH} 8 ; 20 \%$ sucrose, no $\mathrm{FeSO}_{4}$ ) while hygromycin was applied to regenerated protoplasts $24 \mathrm{~h}$ after transformation by overlay agar at a concentration of $1.5 \mathrm{mg} / \mathrm{ml}$. Resistant colonies were transferred to fresh selective medium (BII, $\mathrm{pH} 8$, with phleomycin at $100 \mu \mathrm{g} / \mathrm{ml}$ or BII, pH 8, with hygromycin at $0.5 \mathrm{mg} / \mathrm{ml}$ ) and subjected to at least one single-spore isolation to obtain homokaryotic strains. Conidial isolates were obtained by spreading conidial suspensions on selective media and transferring single colonies to new plates. PCR was done to identify homologous integration events. To verify integration of the $5^{\prime}$ flank in putative $\Delta$ nox 2 deletion mutants, the primers $5^{\prime} \mathrm{NCR}$ cpnox 2 down and TrpC-Ter were used. To analyze the integration of the $3^{\prime}$ flank, the primers gpd-Pro and Nox2_dia3'neu were used. The lack of the wild-type gene copy in the $\Delta$ cpnox 2 mutants was checked using the primers nox2_WT_hin and Nox2_dia3'neu.

In order to ensure that only one copy of the replacement fragment had integrated into the genome of $\mathrm{Cp} 20.1$, and to confirm the deletion of cpnox2, Southern analysis was performed. BamHI-digested genomic DNA of strains 20.1 and $\Delta$ cpnox 2 was probed with an EcoRV/BamHI fragment from the $3^{\prime}$ flank of cpnox 2 .

For complementation of the mutant, $\Delta$ cpnox 2 was transformed with the circular cpnox2_comp construct carrying the phleomycin resistance gene. Resulting resistant transformants were checked for the reintegration of cpnox 2 by PCR.

The homologous integration of the deletion fragment of cpplsl was verified via diagnostic PCRs using dia_pls1LF_fwd and TrpC-Ter for the $5^{\prime}$ flank and dia_pls1-RF_rev /phleo_out-Hefe 3 to verify the integration of the $3^{\prime}$ flank. In addition, the primer combination dia_pls1-wt_fwd dia_pls1RF_rev was used as a control for the lack of the wild-type gene copy.

To exclude additional integrations of the replacement fragment into the $\Delta$ cppls1 deletion mutant, Southern analysis was performed using XhoI-digested genomic DNA probed with the $3^{\prime}$ flank of cppls1. Complementation of $\Delta$ cppls1 was performed using the GFP::CpPls1 fusion protein construct.

\section{Pathogenicity assays.}

Rye plants were cultivated in growth chambers as described by Smit and Tudzynski (1992). For in planta pathogenicity assays, florets of blooming ears (30 to 40 florets per ear) were inoculated with $5 \mu \mathrm{l}$ of a suspension containing $2 \times 10^{6}$ conidia/ml collected from Mantle agar, as described by Tenberge and associates (1996), as well as with mycelial suspensions, respectively. To avoid cross contaminations, the ears were covered with paper bags equipped with Cellophane windows directly after inoculation or separated from one another by plastic collars.
The in vitro pathogenicity assay was performed as described by Scheffer and Tudzynski (2006). Ovaries of blooming rye ears were dissected, embedded into Hoagland media, and inoculated with $1 \mu \mathrm{l}$ of a conidiospore suspension. The ovaries were cultivated at $18^{\circ} \mathrm{C}$ with $14 \mathrm{~h}$ of light for 3 to 7 days.

\section{Microscopic analyses.}

For microscopy of fusion proteins, the corresponding strains were cultivated on microscope slices covered with thin layers of Gamborg's B5 medium (Duchefa Biochemie BV, Haarlem, The Netherlands). For detection of fungal nuclei, nucleic acids were stained by application of fluorescent dye Hoechst 33342. Hoechst $(10 \mu \mathrm{l})$ solution prepared according to Kangatharalingam and Ferguson (1984) was applied to the fungal hyphae before microscopy. For staining of the ER, a 1:50 dilution of ER-Tracker Blue-White DPX (Life Technologies, Carlsbad, CA, U.S.A.) in McIlvaine standard buffer was added to the hyphae before microscopy. Fluorescence and light microscopy were performed with a Zeiss AxioImager M1 microscope. Hoechst staining and the ER-Tracker were examined using the filter set 49 4',6-diamidino-2-phenylindole shift free (excitation G 365, beam splitter FT 395, and emission BP 445/50), GFP fluorescence with filter set 38 (excitation BP 470/40, beam splitter FT 495, and emission BP 525/50), and mCherry fluorescence using filter set $43 \mathrm{HE}$ Cy 3 shift free (excitation BP 550/25, beam splitter FT 570, and emission BP 605/70). Images were captured with a Zeiss AxioCam MRm camera and analyzed using the Axiovision Rel 4.8 software package.

For microscopic study, in planta rye ovaries were stained with $\mathrm{KOH}$-aniline-blue as described by Scheffer and Tudzynski (2006) and examined with a Zeiss DiscoveryV20 stereomicroscope fitted with an AxioCam MRc camera. Image analysis was performed with Axiovision Rel 4.8 software.

\section{Generation of yeast two-hybrid vectors.}

CpRac vectors for yeast two-hybrid analyses were constructed by the yeast recombinational method (Schumacher 2012). Therefore, cDNA fragments were amplified using the primers BD-rac-F and BD-rac-R. For wild-type CpRac, cDNA of $C$. purpurea 20.1 was used as a template, whereas dominant active $(\mathrm{G} 14 \mathrm{~V})$ and dominant negative $(\mathrm{T} 22 \mathrm{~N}) \mathrm{CpRac}$ were amplified from respective pAD-Gal4-2.1 vectors $\mathrm{pADrac}^{\mathrm{G} 17 \mathrm{~V}}$ and pADrac ${ }^{\text {T22N }}$ (Rolke and Tudzynski 2008). Yeast strain SMY3 (Cardenas et al. 1994) was co-transformed with fragments and an SalI/EcoRI-digested pBD-Gal4 vector from Stratagene. Selection was performed on SD medium lacking tryptophan for $\mathrm{pBD}$ transformants. Yeast plasmid DNA was extracted using the SpeedPrep yeast plasmid isolation kit (DualSystems, Schlieren, Switzerland) and expressed in E. coli for further analysis.

The CpNoxR vectors for yeast two-hybrid analyses were constructed via a classical restriction and ligation approach. Primers noxRy $2 \mathrm{hEco} 1 \mathrm{~F}$ and noxRy $2 \mathrm{hSal} 1 \mathrm{R}$ were used to amplify the respective cpnoxR fragment from cDNA which was then cloned into the pCR2.1 TOPO vector for sequencing, excised with EcoR1 and Sal1, and ligated into SalI/EcoRIdigested $\mathrm{pAD}$ or $\mathrm{pBD}$ vectors.

\section{Yeast two-hybrid assay.}

The yeast two-hybrid assay was performed according to the description of Fields and Song (1989). The yeast strain pJ694A (James et al. 1996) was co-transformed with the respective plasmid combinations by the lithium-acetate method described in Woods and Gietz (2001). The strains were incubated for 5 days on SD medium lacking leucine and tryptophan to select co-transformants. For drop tests, the strains were grown over- 
night in $5 \mathrm{ml}$ of liquid SD and adjusted to an optical density at $600 \mathrm{~nm}$ of 1 . Cells were starved in $1 \mathrm{M}$ Sorbitol for $5 \mathrm{~h}$ at $30^{\circ} \mathrm{C}$ and serial dilutions of $1: 10,1: 100$, and $1: 1000$ were prepared. Dilutions $(10 \mu \mathrm{l})$ were spotted on to SD-leu-trp and SDleu-trp-his $+3 \mathrm{mM}$ 3AT plates and grown at $30^{\circ} \mathrm{C}$ for 6 days. General growth of the strains was checked by observing growth on SD-leu-trp plates, whereas interaction was indicated by growth on SD-leu-trp-his+3AT medium.

\section{ACKNOWLEDGMENTS}

We thank T. Schürg for providing the cpnox2 replacement vector, D. Odinius for excellent technical assistance, B. Williamson for critical reading of the manuscript, and the DFG for funding (Tu50/17). J. Schürmann was holder of a research fellowship of the DFG Graduate school 1409. J. Schürmann and D. Buttermann contributed equally to this article. All authors contributed significantly to the conception, design, analysis, and interpretation of data; to drafting the article and revising it critically for important intellectual content; and to final approval of the version to be submitted. D. Buttermann, J. Schürmann, and A. Hermann were involved in the performance of experiments and P. Tudzynski was responsible for the final draft and submission.

\section{LITERATURE CITED}

Aguirre, J., Ríos-Momberg, M., Hewitt, D., and Hansberg, W. 2005. Reactive oxygen species and development in microbial eukaryotes. Trends Microbiol. 13:111-118.

Alderman, S. C. 2003. Diversity and speciation in Claviceps. Pages 19524 in: Clavicipitalean Fungi: Evolutionary Biology, Chemistry, Biocontrol and Cultural Impacts. Mycology 19. J. F. White, C. W. Bacon, N. L. Hywel-Jones, and J. W. Spatafora, eds. Marcel Dekker, New York.

Altschul, S. F., Madden, T. L., Schäffer, A. A., Zhang, J., Zhang, Z., Miller W., and Lipman, D. J. 1997. Gapped BLAST and PSI-BLAST: A new generation of protein database search programs. Nucleic Acids Res. 24:3389-3402.

Ambasta, R. K., Kumar, P., Griendling, K. K., Schmidt, H. H., Busse, R., and Brandes, R. P. 2004. Direct interaction of the novel Nox proteins with $\mathrm{p} 22$ phox is required for the formation of a functionally active NADPH oxidase. J. Biol. Chem. 279:45935-45941.

Ausubel, F. M., Brent, R., Kingston, R. E., Moore, D. D., Seidmann, J. G., Smith, J. A., and Struhl, K. 1987. Current Protocols in Molecular Biology. John Wiley and Sons, New York.

Bertani, G. 1951. Studies on lysogenesis. I. The mode of phage liberation by lysogenic Escherichia coli. J. Bacteriol. 62:293-300.

Bové, F. J. 1970. The Story of Ergot. S. Karger, Basel, Switzerland.

Bretscher, M. S., and Munro, S. 1993. Cholesterol and the golgi-apparatus. Science 261:1280-1281.

Brockmann, B., Smit, R., and Tudzynski, P. 1992. Characterization of an extracellular $\beta$-1,3-glucanase of Claviceps purpurea. Physiol. Mol. Plant Pathol. 40:191-201.

Cano-Dominguez, N., Alvarez-Delfín, K., Hansberg, W., and Aguirre, J. 2008. NADPH oxidases NOX-1 and NOX-2 require the regulatory subunit NOR-1 to control cell differentiation and growth in Neurospora crassa. Eukaryot. Cell 7:1352-1361.

Cardenas, M. E., Hemenway, C., Muir, R. S., Ye, R., Fiorentino, D., and Heitman, J. 1994. Immunophilins interact with calcineurin in the absence of exogenous immunosuppressive ligands. EMBO (Eur. Mol. Biol. Organ.) J. 13:5944-5957.

Cenis, J. L. 1992. Rapid extraction of fungal DNA for PCR amplification. Nucleic Acid Res. 20:2380.

Chenevert, J., Corrado, K., Bender A., Pringle, J., and Herskowitz, I. 1992. A yeast gene (BEM1) necessary for cell polarization whose product contains two SH3 domains. Nature 356:77-79.

Chin, C.F., Bennett, A. M., Ma, W. K., Hall, M. C., and Yeong F. M. 2012. Dependence of Chs 2 ER export on dephosphorylation by cytoplasmic Cdc14 ensures that septum formation follows mitosis. Mol. Biol. Cell 23:45-58.

Christianson, T. W., Sikorski, R. S., Dante, M., Shero, J. H., and Hieter, P. 1992. Multifunctional yeast high-copy-number shuttle vectors. Gene 110:119-122.

Clergeot, P. H., Gourgues, M., Cots, J., Laurans, F., Latorse, M. P., Pepin, R., Tharreau, D., Notteghem, J. L., and Lebrun, M. H. 2001. PLS1, a gene encoding a tetraspanin-like protein, is required for penetration of rice leaf by the fungal pathogen Magnaporthe grisea. Proc. Natl. Acad. Sci. U.S.A. 98:6963-6968.

Colot, H. V., Park, G., Turner, G. E., Ringelberg, C., Crew, C. M.,
Litvinkova, L., Richard, L., Weiss, R. L., Borkovich, K. A., and Dunlap J. C. 2006. A high-throughput gene knockout procedure for Neurospora reveals functions for multiple transcription factors. Proc. Natl. Acad. Sci. U.S.A. 103:10352-10357.

Corbett, K., Dickerson, A. G., and Mantle, P. G. 1975. Metabolism of the Germinating Sclerotium of Claviceps purpurea. J. Gen. Microbiol. 90:55-68

Däubner, T., Fink, A., Seitz, A., Tenzer S., Müller J., Strand, D., Seckert, C. K., Janssen, C., Renzaho, A., Grzimek, N. K. A., Simon, C. O. Ebert, S., Reddehase, M. J., Oehrlein-Karpi, S. A., and Lemmermann, N. A. W. 2010. A novel transmembrane domain mediating retention of a highly motile herpesvirus glycoprotein in the endoplasmic reticulum. J. Gen. Virol. 91:1524-1534.

Egan, M. J., Wang, Z. Y., Jones, M. A., Smimoff, N., and Talbot, N. J. 2007. Generation of reactive oxygen species by fungal NADPH oxidases is required for rice blast disease. Proc. Natl. Acad. Sci. U.S.A. 104:11772-11777.

Fields, S., and Song, 0. K. 1989. A novel genetic system to detect proteinprotein interactions. Nature 340:245-246.

Franck, B. 1969. Structure and biosynthesis of the Ergot pigments. Angew. Chem. Int. Ed. Engl. 8:251-260.

Georgiou, C. D., Tairis, N., and Sotiropoulou, A. 2000. Hydroxyl radical scavengers inhibit sclerotial differentiation and growth in Sclerotinia sclerotiorum and Rhizoctonia solani. Mycol. Res. 104:1191-1196.

Georgiou, C. D., Patsoukis, N., Papapostolou, I., and Zervoudakis, G. 2006. Sclerotial metamorphosis in filamentous fungi is induced by oxidative stress. Integr. Compar. Biol. 46:691-712.

Giesbert, S., Schürg, T., Scheele, S., and Tudzynski, P. 2008. The NADPH oxidase Cpnox 1 is required for full pathogenicity of the Ergot fungus Claviceps purpurea. Mol. Plant Pathol. 9:317-327.

Gourgues, M., Brunet-Simon, A., Lebrun, M. H., and Levis, C. 2004. The tetraspanin $\mathrm{BcPls} 1$ is required for appressorium-mediated penetration of Botrytis cinerea into host plant leaves. Mol. Microbiol. 51:619-629.

Haarmann, T., Rolke, Y., Giesbert, S., and Tudzynski, P. 2009. Ergot: From witchcraft to biotechnology. Mol. Plant Pathol. 10:563-577.

Hansberg, W., and Aguirre, J. 1990. Hyperoxidant states cause microbial cell differentiation by cell isolation from dioxygen. J. Theor. Biol. 142:201-221.

Harper, J. W., Adami, G. R., Wei, N., Keyomarsi, K., and Elledge, S. J. 1993. The p21 Cdk-interacting protein Cipl is a potent inhibitor of Gl cyclin-dependent kinases. Cell 75:805-816.

Heller, J., and Tudzynski, P. 2011. Reactive oxygen species in phytopathogenic fungi: Signaling, development, and disease. Annu. Rev. Phytopathol. 49:369-390

Hemler, M. E. 2003. Tetraspanin proteins mediate cellular penetration, invasion and fusion events, and define a novel type of membrane microdomain. Annu. Rev. Cell Dev. Biol.19:397-422.

Hemler, M. E. 2005. Tetraspanin functions and associated microdomains. Nat. Rev. Mol. Cell Biol. 6:801-811.

Hüsgen, U., Büttner, P., Müller, U., and Tudzynski, P. 1999. Variation in karyotype and ploidy level among field isolates of Claviceps purpurea. J. Phytopathol. 147:591-597.

James, P., Halladay, J., and Craig, E. A. 1996. Genomic libraries and a host strain designed for highly efficient two-hybrid selection in yeast. Genetics 144:1425-1436.

Jungehülsing, U., Arntz, C., Smit, R., and Tudzynski, P. 1994. The Claviceps purpurea glyceraldehyde-3-phosphate dehydrogenase gene: Cloning, characterization, and use for the improvement of a dominant selection system. Curr. Genet. 25:101-106.

Kangatharalingam, N., and Ferguson, M. W. 1984. A simple and rapid technique for fluorescence staining of fungal nuclei. Curr. Microbiol. 10:99-104.

Kawahara, T., and Lambeth, J. D. 2007. Molecular evolution of Phoxrelated regulatory subunits for NADPH oxidase enzymes. BMC Evol. Biol. 7:178.

Kim, H. J., Chen, C., Kabbage, M., and Dickman, M. B. 2011. Identification and characterization of Sclerotinia sclerotiorum NADPH oxidases. Appl. Environ. Microbiol. 77:7721-7729.

Kirchhoff, H. 1929. Beiträge zur Biologie und Physiologie des Mutterkornpilzes. Centralbl. Bakteriol. Parasitenk. Abt. II. 77:310-369.

Lambeth, J. D. 2004. NOX enzymes and the biology of reactive oxygen. Nat. Rev. Immunol. 4:181-189.

Lambou, K., Malagnac, F., Barbisan, C., Tharreau D., Lebrun, M. H., and Silar, P. 2008. The crucial role of the Pls1 tetraspanin during ascospore germination in Podospora anserina provides an example of the convergent evolution of morphogenetic processes in fungal plant pathogens and saprobes. Eukaryot. Cell 7:1809-1818.

Lara-Ortiz, T., Riveros-Rosas, H., and Aguirre, J. 2003. Reactive oxygen species generated by microbial NADPH oxidase NoxA regulate sexual development in Aspergillus nidulans. Mol. Microbiol. 50:1241-1255. 
Levy, S., and Shoham T. 2005. The tetraspanin web modulates immunesignalling complexes. Nat. Rev. Immunol. 5:136-148.

Luttrell, E. S. 1980. Host-parasite relationships and development of the Ergot sclerotium in Claviceps purpurea. Can. J. Bot. 58:942-958.

Malagnac, F., Lalucque, H., Lepère, G., and Silar, P. 2004. Two NADPH oxidase isoforms are required for sexual reproduction and ascospore germination in the filamentous fungus Podospora anserina. Fungal Genet. Biol. 41:982-997.

Mantle, P. G., and Nisbet, L. J. 1976. Differentiation of Claviceps purpurea in axenic culture. J. Gen. Microbiol. 93:321-334.

Marchler-Bauer, A., Lu, S., Anderson, J. B., Chitsaz, F., Derbyshire, M. K., DeWeese-Scott, C., Fong, J. H., Geer, L. Y., Geer, R. C., Gonzales, N. R., Gwadz, M., Hurwitz, D. I., Jackson, J. D., Ke, Z., Lanczycki, C. J., Lu, F., Marchler, G. H., Mullokandov, M., Omelchenko, M. V., Robertson, C. L., Song, J. S., Thanki, N., Yamashita, R. A., Zhang, D., Zhang, N., Zheng, C., and Bryant, S. H. 2011. CDD: A conserved domain database for the functional annotation of proteins. Nucleic Acids Res. 39:D225-D229.

Moore, S., de Vries, O. M., and Tudzynski, P. 2002. The major Cu, Zn SOD of the phytopathogen Claviceps purpurea is not essential for pathogenicity. Mol. Plant Pathol. 3:9-22.

Müller, U., Tenberge, K. B., Oeser, B., and Tudzynski, P. 1997. Cel1, probably encoding a cellobiohydrolase lacking the substrate binding domain, is expressed in the initial phase of Claviceps purpurea on Secale cereale. Mol. Plant-Microbe Interact. 10:268-279.

Petry, A., Djordjevic, T., Weitnauer, M., Kietzmann, T., Hess, J., and Görlach, A. 2006. NOX2 and NOX4 mediate proliferative response in endothelial cells. Antioxid. Redox. Signal. 8:1473-1484.

Rinnerthaler, M., Büttner, S., Laun, P., Heeren, G., Felder, T. K., Klinger, H., Weinberger, M., Stolze, K., Grousl, T., Hasek, J., Benada, O., Frydlova, I., Klocker, A., Simon-Nobbe, B., Jansko, B., BreitenbachKoller, H., Eisenberg, T., Gourlay, C. W., Madeo, F., Burhans, W. C., and Breitenbach, M. 2012. Ynolp/Aim14p, a NADPH-oxidase ortholog, controls extramitochondrial reactive oxygen species generation, apoptosis, and actin cable formation in yeast. Proc. Natl. Acad. Sci. U.S.A. 109:8658-8663.

Rolke, Y., and Tudzynski, P. 2008. The small GTPase Rac and the p21activated kinase Cla4 in Claviceps purpurea: Interaction and impact on polarity, development and pathogenicity. Mol. Microbiol. 68:405-423.

Ryder, L. S., Dagdas, Y. F., Mentlak, T. A, Kershawa, M. J., Thornton, C. R., Schuster, M., Chen, J., Wang, Z., and Talbot, N. J. 2013. NADPH oxidases regulate septin-mediated cytoskeletal remodeling during plant infection by the rice blast fungus. Proc. Natl. Acad. Sci. U.S.A. 110:3179-3184

Sambrook, J., Fritsch, E. F., and Maniatis, T. 1989. Molecular Cloning: A Laboratory Manual, 2nd ed. Cold Spring Harbor Laboratory Press, Cold Spring Harbor, NY, U.S.A.

San Martín A., and Griendling, K. K. 2010. Redox control of vascular smooth muscle migration. Antioxid. Redox. Signal. 12:625-640.

Schardl, C., Young, C., Hesse, U., Amyotte, S. G., Andreeva, K., Calie, P. J., Fleetwood, D. J., Haws, D. C., Moore, N., Oeser, B., Panaccione, D. G. , Schweri, K. K., Voisey, C. R., Farman, M. L., Jaromczyk, J. W., Roe, B. A., O’Sullivan, D. M. , Scott, B., Tudzynski, P., An, Z., Arnaoudova, E. G., Bullock, C. T., Charlton, N. D., Chen, L., Cox, M., Dinkins, R. D., Florea, S., Glenn, A. E., Gordon, A., Güldener, U., Harris, D. R. Hollin, W., Jaromczyk, J., Johnson, R. D., Khan, A. K., Leistner E., Leuchtmann, A., Li, C., Liu, J. G., Liu, J., Liu, M., Mace, W., Machado, C., Nagabhyru, P., Pan, J., Schmid, J., Sugawara, K., Steiner, U., Takach, J. E., Tanaka, E., Webb, J. S., Wilson, E. V., Wiseman, J. L., Yoshida, R., and Zeng, Z. 2013. Plant-symbiotic fungi as chemical engineers: Multi-genome analysis of the clavicipitaceae reveals dynamics of alkaloid loci. PLoS Genet. 9:e1003323. Published online.

Scheffer, J., and Tudzynski, P. 2006. In vitro pathogenicity assay for the Ergot fungus Claviceps purpurea. Mycol. Res. 110:465-470.

Scheffer, J., Chen, C., Heidrich, P., Dickman, M. B., and Tudzynski, P. 2005 A CDC42 homologue in $C$. purpurea is involved in vegetative differentiation and is essential for pathogenicity. Eukaryot. Cell 4:1228-1238.

Schumacher, J. 2012. Tools for Botrytis cinerea: New expression vectors make the gray mold fungus more accessible to cell biology approaches. Fungal Genet. Biol. 49:483-497.

Schürg, T., Brandt, U., Adis, C., and Fleissner, A. 2012. The Saccharomyces cerevisiae BEM1 homologue in Neurospora crassa promotes coordinated cell behaviour resulting in cell fusion. Mol. Microbiol. 86:349-66.
Schürmann, J., and Tudzynski, P. Claviceps: The ergot fungus. In: Molecular Biology of Food and Water Borne Mycotoxigenic and Mycotic Fungi of Humans. R. Russell and M. Paterson, eds. CRC Press, Boca Raton, FL, U.S.A. In press.

Segmüller, N., Kokkelink, L., Giesbert, S., Odinius, D., van Kan, J., and Tudzynski, P. 2008. NADPH oxidases are involved in differentiation and pathogenicity in Botrytis cinerea. Mol. Plant-Microbe Interact. 21:808-819.

Shaw, B. I., and Mantle, P. G. 1980. Host infection by Claviceps purpurea. Trans. Br. Mycol. Soc. 75:77-90.

Siegmund, U., Heller, J., van Kan, J., and Tudzynski, P. 2013. The NADPH oxidase complexes in Botrytis cinerea: Evidence for a close association with the ER and the tetraspanin Pls1. PLoS One 8:e55879. Published online.

Smit, R., and Tudzynski, P. 1992. Efficient transformation of Claviceps purpurea using pyrimidine auxotrophic mutants: Cloning of the OMP decarboxylase gene. Mol. Gen. Genet. 234:297-305.

Sonnhammer, E. L. L., von Heijne, G., and Krogh, A. 1998. A hidden Markov model for predicting transmembrane helices in protein sequences. Pages 175-182 in: Proceedings of the Sixth International Conference on Intelligent Systems for Molecular Biology. J. Glasgow, T. Littlejohn, F. Major, R. Lathrop, D. Sankoff, and C. Sensen, eds. AAAI Press, Menlo Park, CA, U.S.A.

Sumimoto, H., Kamakura, S., and Ito, T. 2007. Structure and function of the PB1 domain, a protein interaction module conserved in animals, fungi, amoebas, and plants. Sci. STKE. 10.1126/stke.4012007re6. Published online.

Taber, W. A. 1985. Biology of Claviceps. Pages 449-486 in: Biotechnology Series, Vol. 6. Biology of Industrial Microorganisms. A. L. Demain and A. S. Nadine, eds. The Benjamin Cummings Publishing Co., Inc., New York.

Takemoto, D., Tanaka, A., and Scott, B. 2006. A p67phox-like regulator is recruited to control hyphal branching in a fungal-grass mutualistic symbiosis. Plant Cell 18:2807-2821.

Takemoto, D., Tanaka, A., and Scott, B. 2007. NADPH oxidases in fungi: Diverse roles of reactive oxygen species in fungal cellular differentiation. Fungal Genet. Biol. 44:1065-1076.

Takemoto, D., Kamakura, S., Saikia, S., Becker, Y., Wrenn, R., Tanaka, A. Sumimoto, H., and Scott, B. 2011. Polarity proteins Bem1 and Cdc24 are components of the filamentous fungal NADPH oxidase complex. Proc. Natl. Acad. Sci. U.S.A. 108:2861-2866.

Tanaka, A., Christensen, M. J., Takemoto, D., Park, P., and Scott, B. 2006 Reactive oxygen species play a role in regulating a fungus-perennial ryegrass mutualistic interaction. Plant Cell 18:1052-1066.

Tenberge, K. B., Homann, V., Oeser, B., and Tudzynski, P. 1996. Structure and expression of two polygalacturonase genes of Claviceps purpurea oriented in tandem: Cytological evidence for pectinolytic enzyme activity during infection of rye. Phytopathology 86:1084-1097.

Thines, E., Weber, R. W. S., and Talbot, N. J. 2000. MAP kinase and protein kinase A-dependent mobilization of triacylglycerol and glycogen during appressorium turgor generation by Magnaporthe grisea. Plant Cell 12:1703-1718.

Tu, L., Sun, T. T., and Kreibich, G. 2002. Specific heterodimer formation is a prerequisite for uroplakins to exit from the endoplasmic reticulum. Mol. Biol. Cell 13:4221-4230.

Tudzynski, P., Heller J., and Siegmund U., 2012. Reactive oxygen species generation in fungal development and pathogenesis. Curr. Opin. Microbiol. 15:653-659.

Veneault-Fourrey, C., Parisot, D., Gourgoues, M., Laugé, R., Lebrun, M. H., and Langin, T. 2005. The tetraspanin gene CIPLS1 is essential for appressorium-mediated penetration of the fungal pathogen Colletotrichum lindemuthianum. Fungal Genet. Biol. 42:306-318.

Winston, F., Dollard, C., and Ricupero-Hovasse, S. L. 1995. Construction of a set of convenient Saccharomyces cerevisiae strains that are isogenic to S288C. Yeast 11:53-55.

Woods, R. A., and Gietz, R. D. 2001. High-efficiency transformation of plasmid DNA into yeast. Methods Mol. Biol. 177:85-97.

Wu, R. F., Ma, Z., Liu, Z., and Terada, L. S. 2010. Nox4-derived $\mathrm{H}_{2} \mathrm{O}_{2}$ mediates endoplasmatic reticulum signaling through local Ras activation. Mol. Cell. Biol. 30:3553-3568.

Zhang, L., Nguyen, M. V., Lardy, B., Jesaitis, A.J., Grichine, A., Rousset, F., Talbot, M., Paclet, M., Qian, G., and Morel, F. 2011. New insight into the Nox4 subcellular localization in HEK293 cells: First monoclonal antibodies against Nox4. Biochimie 93:457-468. 